\title{
Downstream Processing Stages, Comparative Analysis \& Extraction Methodologies in Generation of Cannabinoids from Cannabis Sativa L. (Hemp)
}

\section{Author: Lakshya Sharma1}

\begin{abstract}
Due to the intoxicating effects of only a few cannabinoids, the cannabis plant has long been prohibited by legislation in several countries. Recent scientific advancements, along with a growing public awareness of cannabis as a medicinal commodity, prompted law reform, resulting in a historic shift in which demand increased tenfold in less than five years. The technology necessary for cannabis processing and extraction of the most valuable chemical components from the cannabis flower, on the other hand, remains the processing bottleneck. The downstream processing stages and concepts involved in generating cannabinoids from Cannabis Sativa L. (Hemp) biomass are discussed in this study. I evaluated and criticised several pre-treatment procedures and technical alternatives available for large-scale extraction in both categories by dividing extraction technology into seed and trichome. The major focus was on solvent extraction methods, as well as the important decision-making criteria at each stage and the applicable contemporary technology in the sector. I looked at the variables that impact cannabis transformation and how they affect the medicinal functioning of the finished goods. According to current trends, extraction technologies are constantly reviewed and improved, yet they still fall short of market demands. Cannabis sativa has hundreds of bioactive chemicals, making it one of the oldest therapeutic plants utilised by humans. Although the plant's medicinal benefits are undeniable, the biological consequences and interaction of these chemicals are yet unknown. These chemicals' extraction techniques are becoming an important element of current Cannabis-based therapy. Despite this, little is known about how different techniques impact the final composition of Cannabis extracts and, as a result, their medicinal benefits. Different extraction methods, such as maceration, Soxhlet, ultrasound-assisted extraction, and supercritical $\mathrm{CO}_{2}$ extraction methods, were evaluated in this study.
\end{abstract}

\footnotetext{
${ }^{1}$ Corresponding Author: Lakshya Sharma, Student, Delhi Public School, Sector 45, Gurgaon slakshya61@gmail.com
} 
The extracts were tested in vitro on human colon cancer and healthy colon cells for cannabis content, antioxidant effects, and in vitro bioactivity. Findings indicate that properly produced cannabis extracts can dramatically reduce cancer cell viability while sparing healthy cells from harmful effects. However, because post-processing of extracts alters not only the actual quantities of the various cannabinoids, but also their relative ratio to the main extracts, it is difficult to anticipate therapeutic response solely on the composition of the crude extract. These effects must be carefully addressed while developing novel medicinal extracts in the future. The natural non-psychoactive and psychoactive cannabinoids in cannabis are increasing its medicinal relevance. To effectively use the natural cannabinoids for therapeutic and forensic reasons, efficient extraction and quantification are required. In comparison to most conventional extraction methods, the supercritical fluid extraction (SFE) process has gained increasing interest due to its selective extraction, short processing time (partly due to the efficient solvent removal process - supercritical fluid to vapour - leaving a solvent free product), low operating cost, and low environmental impact. Microwave-assisted extraction, solid phase microextraction, hard-cap espresso, Soxhlet extraction, high-throughput homogenization, ultrasound-assisted extraction, vacuum distillation of lipid-based extract, and liquid-liquid extraction are discussed as advantages of SFE of cannabinoids over conventional extraction procedures.

Keywords: Cannabinoids, CBD Purification, Organic Solvent Extraction, Supercritical Fluid Extraction

\section{Introduction}

Hemp, also known as Cannabis sativa L., is an oleaginous plant that has been cultivated by humans for medical purposes and non-edible fibre content for thousands of years. The letter "L" stands for Linnaeus, in honour of Carolus Linnaeus, the father of modern taxonomy, who was the first to name the species Cannabis sativa.

Cannabinoids such as cannabidiol (CBD), tetrahydrocannabinol (THC), cannabichromene $(\mathrm{CBC})$, cannabigerol $(\mathrm{CBG})$, and cannabinol are all found in abundance in this plant (CBN). Cannabinoids are demonstrated to have potent anti-inflammatory, anti-depressant, anti-nausea, anti-epileptic, and anti-epileptic properties. In China, cannabis was first used almost 5000 years 
ago. Since then, hemp use has been fueled by its diverse variety of qualities and applications, which have been passed down from one culture to the next through millennia.

Yamauchi et al., to the best of these authors' knowledge, did the first academic research on the extraction of hemp bioactive components in the late 90's. Hemp is classified as a member of the Cannabinaceae family, which has three subspecies, namely Sativa, Indica, and Ruderalis. The primary variations between these three subspecies are in the plant's general form, uses, and the best climate for its growth.

The classification of cannabis strains as hemp or marijuana is just incorrect nomenclature that is completely misunderstood when compared to a larger definition of cannabis. The two names distinguish types that contain less than 0.3 weight $\%$ ( $\Delta 9$-THC) (hemp) from those that have greater than 0.3 weight $\%(\Delta 9-\mathrm{THC})$ (marijuana) and produce psychoactive effects.

In certain cases, these words are incorrectly adapted and used interchangeably in the literature. This review article does not cover cannabis with a THC concentration of more than $0.3 \%$ (marijuana). Hemp has long been prized for its high-quality fibre and edible oil; but, with the development of synthetic fibres and rising public anti-drug sentiment, it was classified as a restricted substance under 1968 prohibition law.

The manufacturing and development of hemp products were prohibited under drug enforcement laws, putting the United States behind more than 30 other countries that regarded the plant to be an agricultural crop. Commercial hemp farming and research and development were pushed in the United States in the early 1990s. Since then, an increasing number of states have passed laws to enhance state-level research and production.

Marijuana maps, which are constantly updated, show the status of legality, decriminalisation, approval for medicinal use, and particular state legislation. The excellent medicinal effects, as well as the economic advantages to local communities, led to increased public acceptance and eventual legalisation of these drugs in many nations across the world, including lately in many states in the United States.

Beginning with the 2014 Farm Bill, hemp cultivation and growth in the United States saw some respite, and the first medically-oriented legal product hit the market in June 2018, generating a 
massive market for CBD. Despite this, due to the psychoactive qualities of THC, the top limit of 0.3 wt. \% (dry biomass weight) in most U.S. states and the European Union remains a major barrier between the cannabis flower and the drug. According to Arc vision market research, the entire hemp market in the United States was around 700 million dollars in 2017, but with the recent openings, this amount is expected to reach 20 billion dollars by 2024, driving global expenditure to exceed 40 billion dollars.

However, before industrial-scale production standards can be defined, different possible technologies that are both lawful and cost-effective must be developed. Dealing with a live plant that is contentious and inhomogeneous in development owing to varying soil fertility levels and other local circumstances makes determining the best harvesting conditions to achieve the highest THC content difficultly. Establishing effective and energy-efficient largescale extraction procedures, on the other hand, is critical to successfully resolving the difficulties.

Despite the availability of standard lab-scale extraction methods, the variables influencing extraction method selection as well as ultimate extraction yields remain little known. Furthermore, the plant's development and processing are in transition, necessitating the closure of a knowledge gap in the extraction sector in order to build up a full processing system.

\section{Classification of the Extraction Methods}

\subsection{Two Different Contexts of Extraction: Extraction of Cannabinoids \& Terpenes from} Trichomes, Extraction of Fatty Acids or Lipids from Hemp Seeds, Proportion of Male \& Female Plants in a Farm, Quantity of Tetrahydrocannabinol (THC) in Female Plants, Rooting out of Male Plants

The term "extraction" is used in the hemp industry in two different contexts and categories: (a) the trichome category, in which cannabinoids and terpenes are extracted from trichomes with the goal of producing medical or recreational grade supplements; and (b) the seed category, in which fatty acids or lipids are extracted from hemp seeds. 


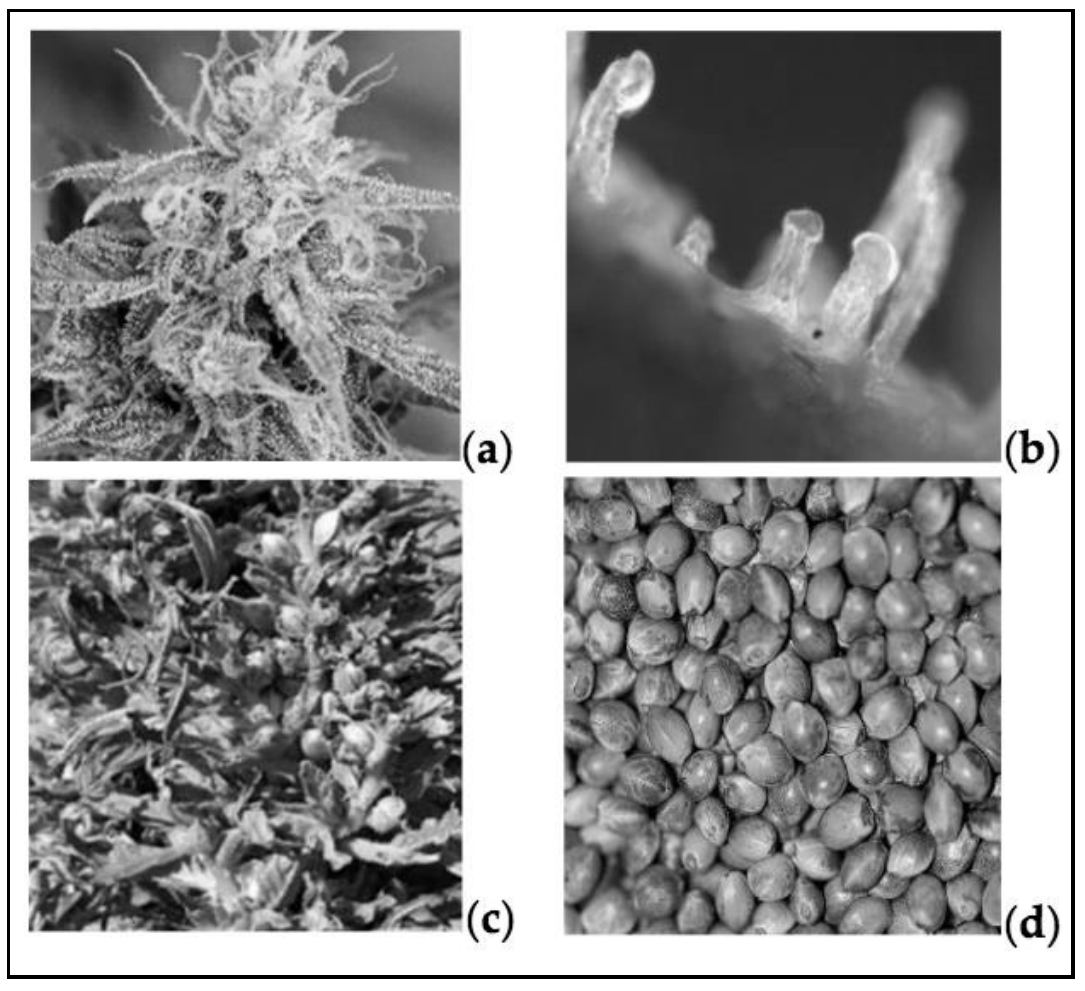

Figure 1: Flower of hemp. Female flower buds with high cannabinoid content before pollination (a) and a microscopic view of the trichomes in the buds (b). Pollination produces the mature seeded flower (c), and pollinated buds create the hempseeds (d).

Triglycerides account for more than $30 \%$ of the weight of hempseed, making them an ideal lipid for transesterification into fatty-acid methyl esters (FAME) or biodiesel. The extracted lipid has a wide range of uses in the cosmetics and food sectors, in addition to biodiesel manufacturing.

This review does not cover the extraction of lipids from seeds (the seed category). I'll cover the procedures involved in cannabinoid and terpene extraction with an emphasis on the trichome category.

If a normal farm produces equal numbers of male and female plants, the ladies will be shorter and have more blooms, while the men will be taller and solely release pollen (Figure 1). Female flowers contain a considerable quantity of THC if picked and dried in a timely manner, whereas male pollen pollinates flower buds to create seeds That is why, prior to pollination, cannabis producers generally root out the male plants. 


\subsection{Extraction of Cannabinoids \& Terpenes from Hemp Flowers: Winterizing, Rotatory}

Evaporation (OSE), Decarboxylation, Fractionation, Chromatographic Procedures for Ultra-Purification (99\%)

Figure 2 depicts the procedures involved in extracting cannabinoids and terpenes from hemp flowers. Some of these stages may be altered depending on the final analytes of interest or the extraction technique used. Hemp flowers should be clipped manually or with the aid of bucking equipment once they've been gathered.

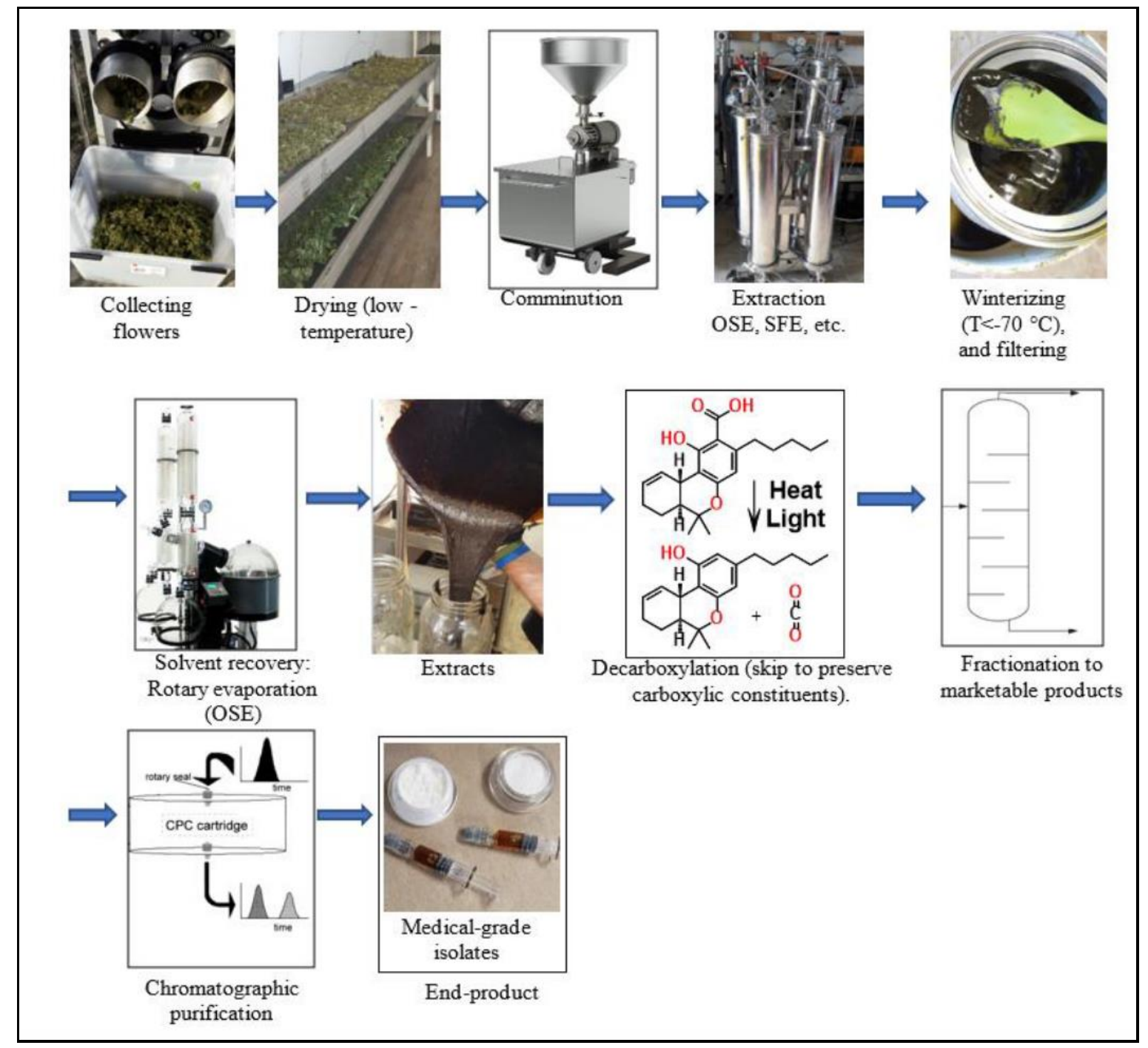

Figure 2: The downstream processing stages required to create cannabinoids from Cannabis sativa $L$. are depicted in this process flow diagram. 
The flowers must next be dried and processed to minimise particle size (in the absence of sunshine to prevent photochemical change). The shredded biomass is placed in extraction tanks and submerged in the solvent(s) of choice for a predetermined amount of time to allow extraction to take place. In addition to cannabinoid and terpene extraction, volatiles, moisture, and heavy residues generally leave the plant matrix as co-extracts when exposed to the solvent.

The latter contains colours, phospholipids, fatty acids, heavy metals, and other substances, and resembles an extremely viscous, sticky black gum that hardens into an inhomogeneous tar when heated. This black substance is wax, and it must be removed before proceeding with the rest of the process since it interferes with the thermodynamics of separation.

Winterization is the process of separating/sedimenting waxy fractions by deep-freezing the crude for over 24 hours and then filtering the solution. The separated wax is utilised in a variety of applications, including electronics, candles, and industrial lubrication. The solvent is extracted using a rotary evaporator and recycled back into the extraction process once it has been winterized. The substance produced can then be distilled into fractions for use as vapes, edibles, topicals, food supplements, or additives.

The products must be ultra-pure (above $99 \%$ purity) for medical or therapeutic purposes, which can be achieved via chromatographic procedures, crystallisation, or distillation processes. Distillation has a number of drawbacks, one of which being the use of heat energy. Neutral cannabinoids (THC, etc.) do not occur in substantial amounts in plants and are often generated after extraction by thermal changes. As a result, extra attention should be used during the process to keep THC levels under control, particularly in the manufacturing of medicinal goods. The next parts will go through this in further detail.

\section{Procedures of Extraction}

3.1 Choosing the right Extraction \& Processing Technique: Polar Solvents, Semi-Polar Cannabinoids, Extracting Compounds through Non-Polar Solvents combined with Screw Expellers \& Overcoming Mass Transfer Obstacles, Mechanical extraction, Soxhlet method, Hot Water Extraction (hydrolysis), DME liquid-liquid Extraction, Supercritical 


\section{$\mathrm{CO}_{2}$ extraction (SC-CO2), Enzyme-assisted Extraction (EAE), Microwave-assisted Extraction}

The extraction step, out of the four main processing phases in the hemp business (variety selection, growing, harvesting, and extraction), is the most important for the total economy and requires the most technological inspection. There are about 500 natural chemical components in Cannabis sativa L. Between 30-60\% of the total cannabinoid in hemp, flowers are lost somewhere during the extraction or purifying process, according to estimates.

With CBD accounting for more than half of the whole cannabis industry, choosing the right extraction and processing technique has a big influence on the overall process economics. The two extraction categories are summarised in Table 1.

A wide range of polar solvents, including methanol, ethanol, isopropanol, dimethyl ether, and others, can be used to extract semi-polar cannabinoids and terpenes from floral trichomes in the trichome (cannabinoid-terpene) category. Dealing with real-time hemp biomass introduces a number of irregularities into the extraction process in both categories; for example, Deferne et al. (1996) reported an inhomogeneous feed of ripe and unripe seeds for the method. As a result, the moisture level of the product rose, the oil production decreased, and the flavour of the product changed.

The cannabinoid composition in the buds is influenced by the amount of moisture in the buds and the plant's overall health. The concentration differential between the solvent media and the trichome surface is the major barrier to chemical transfer since cannabinoids are stored in trichomes outside the buds. It is not necessary to ground or crush the plant vigorously since this increases the solubility of unwanted components.

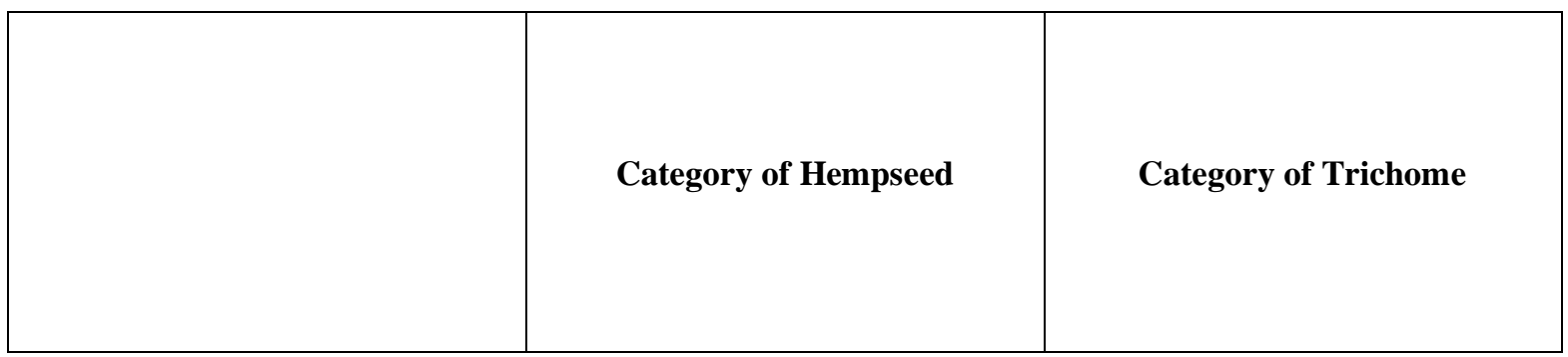




\begin{tabular}{|c|c|c|}
\hline Mass Transfer Driving Force & $\begin{array}{c}\sim\left(\mathrm{C}^{*}-\mathrm{C}\right)=\text { The saturated solution } \\
\text { in contact with the seed particles } \\
\text { and the medium have a } \\
\text { concentration gradient. }\end{array}$ & $\begin{array}{c}-\left(\Delta \mathrm{C}_{\text {trichome-media }}\right)=\text { The difference } \\
\text { in concentration between the } \\
\text { solvent in contact with the } \\
\text { trichome and the medium. }\end{array}$ \\
\hline Co-Extracts & Defatted Oil, Oil Sludges, etc. & Waxes, Pigments, etc. \\
\hline Plant Occurrence & Hempseed & $\begin{array}{l}\text { Female Flower Buds before } \\
\text { Pollination }\end{array}$ \\
\hline Extraction Method & $\begin{array}{l}\text { Cold press, screw expeller } \\
\text { followed by OSE, SFE, or Soxhlet } \\
\text { (small scale only) }\end{array}$ & $\begin{array}{c}\text { OSE, SFE \& Soxhlet (small scale } \\
\text { only) }\end{array}$ \\
\hline Pre-Extraction Treatment & $\begin{array}{l}\text { Mass transmission is improved by } \\
\text { crushing and grinding the seed } \\
\text { into smaller bits. }\end{array}$ & $\begin{array}{l}\text { Mild comminution is adequate; } \\
\text { excessive grinding causes } \\
\text { undesired chemicals to be co- } \\
\text { extracted. }\end{array}$ \\
\hline Solvent Utilized & Nonpolar \& Polar Solvents & Mainly Polar Solvents \\
\hline Chemical Target & Fatty Acids & Cannabinoids \& Terpenes \\
\hline
\end{tabular}


Table 1: In the hemp sector, there are two types of extraction.

The fatty acids found inside hemp seeds are the focus. Nonpolar solvents are used to extract the compounds, which are sometimes combined with screw expellers to squeeze the chemicals out of the plant's fibre structure and overcome mass transfer obstacles. The complicated and multi-step transport of molecules from the seed's inner structure all the way out to the solvent medium governs the extraction kinetics in this category.

Mechanical extraction, Soxhlet method, hot water extraction (hydrolysis), DME liquid-liquid extraction, supercritical $\mathrm{CO}_{2}$ extraction $\left(\mathrm{SC}-\mathrm{CO}_{2}\right)$, enzyme-assisted extraction (EAE), microwave-assisted extraction, and other methods for extracting compounds from hemp are shown in Table 1.

\subsection{Estimating Solute Solubility through Thermodynamic Modelling: Hansen Solubility Parameter (HSP), Solubility Parameter Theory (SPT), Relation of the Distance of the Solvent from the Centre of the Solubility Sphere}

Several thermodynamic models have been suggested to estimate solute solubility in various extraction possibilities, the most commonly recognised of which is the Hansen solubility parameter (HSP). The HSP is based on the solubility parameter theory (SPT), and it provides a mathematical instrument that measures the efficiency of the solute-solvent interaction using Equation:

$$
R_{a}^{2}=4(\Delta \delta)_{D}^{2}+(\Delta \delta)_{M}^{2}+(\Delta \delta)_{H}^{2}
$$

where $\Delta \delta$ ( $\left.=\delta_{\text {solvent }}-\delta_{\text {solute }}\right)$ is the difference between the solubility parameters. The subscripts $\mathrm{D}, \mathrm{M}$, and $\mathrm{H}$ denote the bonding characteristics associated with dispersion (van der Waals), molecule dipolarity, and hydrogen bonding, respectively. The equation can be visualised as a solubility sphere with a radius of $\mathrm{R}_{\mathrm{a}}$ (distance of the solvent from the centre of the solubility sphere), where the closer the analyte's solubility parameters are to those of the solvents $(\Delta \delta \sim 0)$, the closer the solvent is to the centre of the solubility sphere and thus is a suitable solvent. 


\section{Chemical Extraction Methodologies}

\subsection{Cannabis sp. Soxhlet Extraction Processing: Increasing the Polarity of the Solvent by moving from Hexane to Ethyl Acetate and finally to Ethanol Extraction Batches (Polarity Gradient) for extracting entire THC Spectrum, Extracting $\omega$-type acids, Extracting $\Delta^{\mathbf{9}}$ - THC through Soxhlet and pressurised liquid extraction (PLE) methods, Milling for keeping Soxhlet's Efficiency High}

Soxhlet extraction is an ancient but still efficient process for extracting plant oil. Sunn hempseeds, marijuana cigarettes, hashish, coffee, vanillin, rice bran, walnut kernel, fungal biomass, algal oil, orange juice, and other biomass have all been used to extract organics. In the batch process, it runs on a continuous cycle of solvent, leaving the extracts in the extract chamber and contacting the biomass. This equipment accommodates the strongest extraction driving power among all extraction techniques, i.e., the reference method, since it exposes the biomass to a new stream of the organic solvent throughout the process.

Several research studies on the Soxhlet processing of Cannabis sp. for bio-oil extraction have been conducted. However, Cannabis Sativa L. (hemp) has been explored for cannabinoid extraction just a few times in the literature. Matthäus et al. used a different approach to study the fatty-acid content of virgin hemp seed oil and discovered that hemp seeds can contain 2835 wt. \% oil depending on the variety of species, climate and geographical variables, as well as the year of production. Aladic et al. easily achieved the maximum of $35 \mathrm{wt} \%$ using the Soxhlet technique, demonstrating the technology's exceptional capabilities.

Table 2 summarises recent studies on the extraction of different chemicals using the Soxhlet equipment in a concise manner. In a 6-hour period, Molina et al. employed Soxhlet to collect the entire THC content of hemp oil in a step-by-step manner under relatively moderate pressure. They attempted to extract the whole THC spectrum by increasing the polarity of the solvent by moving from hexane to ethyl acetate and finally to ethanol extraction batches (polarity gradient). They eliminated THC molecules attached to distinct cell structures using solvents with varying polarity indices and obtained total THC concentration as the baseline for comparison with other techniques. 
In their search for $\omega$-type acids, Da Porto et al. discovered that Cannabis sativa L. seeds contain $81 \%$ polyunsaturated fatty acids (PUFA), with linoleic acid ( $\omega-6)$ accounting for the majority. Unlike most other researchers, they discovered that $\mathrm{SC}-\mathrm{CO}_{2}$ produced the greatest oil production from hemp seeds, accounting for $22 \%$ of the total recovery and $72 \%$ of the overall yield. This result is slightly lower than Aladic et al Soxhlet .'s extraction result of 28-35\% oil content.

Other cannabinoids have also been extracted and studied. Wianowska et al. used the Soxhlet and pressurised liquid extraction (PLE) methods to extract $\Delta^{9}$-THC, THCA, and cannabinol (CBN) from Cannabis sativa L. and found that the amount of THCA dropped by nearly half while the amount of THC content increased significantly during different time intervals from 1 to $3 \mathrm{~h}$, confirming the transformation of THC from one form to another.

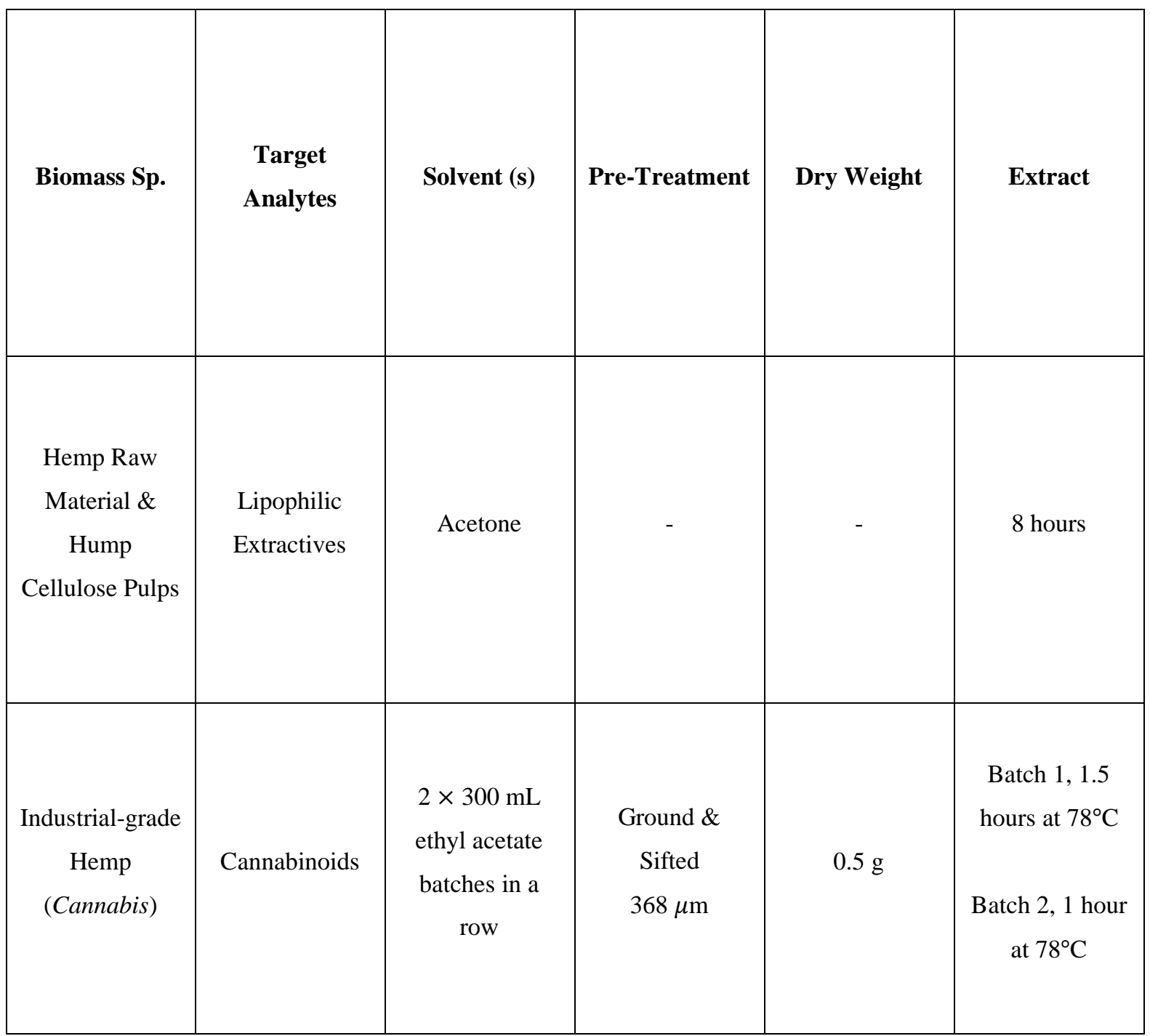




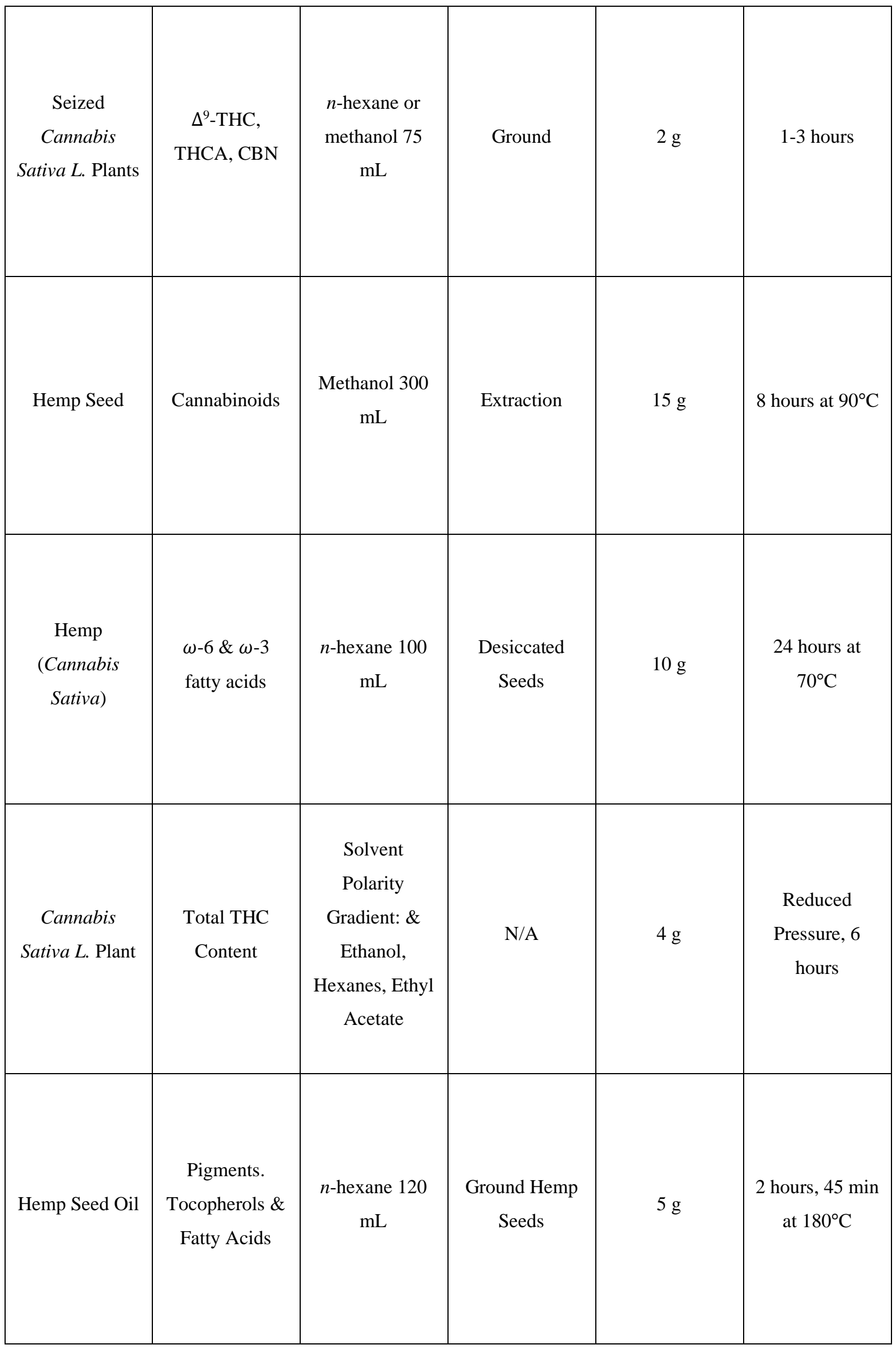




\begin{tabular}{|c|c|c|c|c|c|}
\hline $\begin{array}{c}\text { Industrial } \\
\text { Hemp Dust } \\
\text { Residue }\end{array}$ & $\begin{array}{c}\text { Waxes \& } \\
\text { Cannabidiol } \\
\text { (CBD) C16 } \\
\text { was } \\
\text { predominating }\end{array}$ & $\begin{array}{c}\text { Heptane } 200 \\
\mathrm{~mL}\end{array}$ & $\begin{array}{c}\text { Finely } \\
\text { Powdered } \\
\text { Hemp }\end{array}$ & $11 \mathrm{~g}$ & 4 hours \\
\hline $\begin{array}{c}\text { Cannabis } \\
\text { Sativa } \text { L. Seeds }\end{array}$ & $\begin{array}{c}\text { Fatty Acids, } \\
\text { e.g., } \omega-3 \text { fatty } \\
\text { acids }\end{array}$ & $\begin{array}{c}n \text {-Hexane } 240 \\
\mathrm{~mL}\end{array}$ & $\begin{array}{c}\text { Ground } \\
\text { Hempseed }\end{array}$ & $30 \mathrm{~g}$ & 8 hours at $70^{\circ} \mathrm{C}$ \\
\hline
\end{tabular}

Table 2: Previous investigations employing the Soxhlet technique to extract different chemicals from Cannabis sativa L.

Crescente et al. found that when comparing Soxhlet extraction (with n-hexane) to ultrasonication, microwave irradiation, and supercritical fluid extraction, greater quantities of $\Delta^{9}$-THC were achieved (SFE). The rise in THC was due to the heating that occurred during the extended solvent cycling in Soxhlet. Unlike most previous research, Crescente et al. stated that the total extractable oil obtained by various techniques does not differ much.

Prior treatment of the feed, such as milling depending on particle size and other characteristics of the feed, may be necessary to keep Soxhlet's efficiency reasonably high. Despite its many advantages, Soxhlet's equipment requires a substantial amount of energy to keep the distillation-evaporation cycles going, posing serious upscaling challenges (Table 2). As a result, Soxhlet's apparatus isn't the best option owing to energy waste, time-consuming reloading, fire hazards, and unavoidable side effects including the conversion of THCA to less desired THC.

4.2 Achieving effective Mass Transfer by Immersing the Biomass in the Solvent Media through Maceration Technique: Organic Solvent Extraction (OSE) 
Maceration Method (Immersion), as the name implies, this method entails immersing the biomass in the solvent media for a set period of time in order to achieve effective mass transfer. This broad term encompasses all extraction methods currently in use, including the use of various machines in batch, semi-batch, and continuous forms to provide the required contact between solvent and solute on any scale.

Organic solvent extraction (OSE) methods other than Soxhlet are referred to as immersion/dipping extraction methods in practice. Typically, the extraction method is named after the solvent used, such as ethanol extraction, which involves immersing the biomass in ethanol. Although nonpolar solvents such as hexane have been used for extraction, the latter method is of particular interest for large-scale cannabinoid extraction due to its polar properties.

The involved solvent may differ depending on the target analyte of interest (fatty acid, cannabinoid, or terpenoid); however, when compared to propanol, butanol, and isopropanol, ethanol and methanol have been found to be interesting choices due to their solvent capabilities, relative price, and, more importantly, their boiling point (for recovery purposes). Because of its lower toxicity, ethanol is preferred for medical and dietary applications. Despite the fact that alcohols have long been a popular choice for maceration, Tagen et al. (2020) revealed the details of successful hexane maceration.

After decarboxylation, they obtained a $40 \mathrm{wt}$ \% CBD extracts after a 24-hour maceration at room temperature and solvent recovery. This method is still used in a number of new inventions; for example, several recent patents used modified maceration to extract cannabinoids from hemp.

4.3 Utilizing Safe \& Capable Solvents in their Critical State for Extraction through Supercritical Fluid Extraction: Solvent Power Equation, Mass Transfer Diffusion Rates, Target Compound Solubility through Chemical Interaction by Modifiers (co-solvents), Relative Solubility Parameters ( $\delta$ ), Extracting Terpenolic Camphor through Supercritical CO2 with Anti-Inflammatory Compounds, Depicting the Mutual Behaviour of Cannabinoid Blends through Thermodynamic Modelling 
Traditional organic solvents for extraction have long been criticised for their environmental and safety risks, as well as their high production costs. Supercritical fluid extraction (SFE), a new "green" technology, extracts chemicals by using safe and capable solvents in their critical state. The solvent density increases dramatically as the temperature and pressure rise to the critical state $\left(\mathrm{T}_{\mathrm{c}}\right.$ and $\left.\mathrm{P}_{\mathrm{c}}\right)$, where the fluid can no longer be liquified by increasing the pressure.

This is the most important parameter in the solvent power equation. SFE allows selective extractions because pressure and temperature can be adjusted to tune density and solvent power. Supercritical fluids also have superior mass transfer diffusion rates due to their unique properties (transitional between gas and liquid). Table 3 summarises these distinct physical properties.

Ethene, water, methanol, carbon dioxide, nitrous oxide, sulphur hexafluoride, $n$-butene, and $n$ pentane are among the fluids used in the SFE process.

Supercritical carbon dioxide $\left(\mathrm{SC}-\mathrm{CO}_{2}\right)$ stands out among these candidates and has been widely used because it is abundant, inexpensive, non-toxic, non-flammable, chemically inert, and forms at almost room temperature $\mathrm{T}_{\mathrm{c}}\left(31^{\circ} \mathrm{C}\right)$, which is ideal for thermolabile bioactive compounds.

Furthermore, unlike organic solvents, $\mathrm{SC}-\mathrm{CO}_{2}$ leaves the biomass completely and effortlessly, consuming no energy at the end of cycles and requiring only minor temperature and/or pressure adjustments. Figure 3 shows a schematic of a typical $\mathrm{SC}-\mathrm{CO}_{2}$ extraction process, as well as the necessary equipment. The recovered $\mathrm{CO}_{2}$ is fully recycled back into the chamber for reuse because it is still pure.

\begin{tabular}{|c|c|c|c|}
\hline Material State & Diffusion $\left(\mathbf{m m}^{2} \mathbf{s}^{-1}\right)$ & Viscosity $(\boldsymbol{\mu}$ Pa s) & Density $\left(\mathbf{k g ~ m}^{-3}\right)$ \\
\hline Liquid State & $\sim 0.001$ & $\sim(500-1000)$ & $\sim 1000$ \\
\hline
\end{tabular}




\begin{tabular}{|c|c|c|c|}
\hline Supercritical State & $\sim 0.01$ to 0.1 & $\sim(50-100)$ & $\sim 100$ to 1000 \\
\hline Gas State & $\sim(1-10)$ & $\sim 10$ & $\sim 1$ \\
\hline
\end{tabular}

Table 3: Gases, liquids, and supercritical fluids have a variety of physical characteristics.

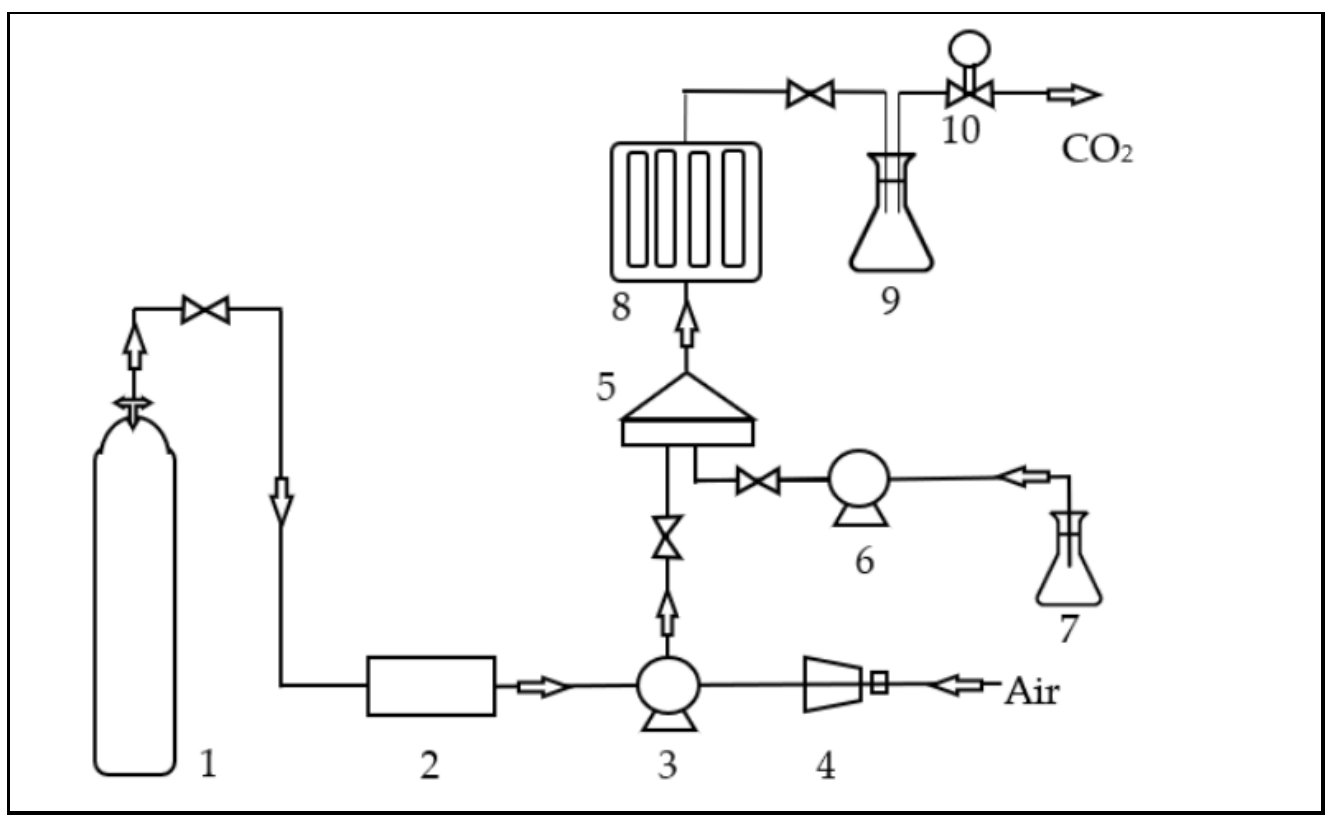

Figure 3: Schematic view of SC- $\mathrm{CO}_{2}$ extraction unit. $\mathrm{CO}_{2}$ cylinder (1); $\mathrm{CO}_{2}$ cooler (2); booster ( $\mathrm{CO}_{2}$ pump-3 and compressor-4); mixer (5); co-solvent pump (6); co-solvent source (7); extraction unit (8); separation vessel (9); flow meter (10).

Modifiers (co-solvents) have been shown to help with target compound solubility by providing a specific chemical interaction with the desired solute. The relative solubility parameters $(\delta)$ of the additives that fall between the co-solvent and the target analytes can justify this.

Acids, water, low molecular-weight alcohols, aldehydes, esters, and ketones have all been reported as cosolvents for $\mathrm{SC}-\mathrm{CO}_{2}$ extraction. Ethanol has been the most commonly used of these. The co-solvent acts as a bridge between the solute and the solvent, allowing for more 
extraction; however, it may also increase unwanted constituent co-extraction, lowering product purity.

\begin{tabular}{|c|c|c|c|c|}
\hline $\begin{array}{c}\text { Name of the } \\
\text { Product }\end{array}$ & The Bambino $^{\circledR}$ & $\mathrm{Hi}^{-F l o}{ }^{\mathrm{TM}} \mathrm{FX} 2$ & E-180 & The Force ${ }^{\circledR}$ \\
\hline $\mathrm{CO}_{2}$ Flow Rate & $0.4-0.8 \mathrm{~kg} \cdot \mathrm{min}^{-1}$ & Up to $95 \%$ & NA & $3.5-4.2 \mathrm{~kg} \cdot \mathrm{min}^{-1}$ \\
\hline $\begin{array}{c}\text { Per Run Dry } \\
\text { Biomass Capacity }\end{array}$ & $1.4 \mathrm{~kg}$ & $4.5 \mathrm{~kg}$ & $10-16 \mathrm{~kg}$ & $18 \mathrm{~kg}$ \\
\hline $\begin{array}{c}\text { Max Pressure of } \\
\text { Vessel }\end{array}$ & 137 bars & 344 bars & 344 bars & 344 bars \\
\hline $\begin{array}{c}\text { Volume of } \\
\text { Extraction Vessel }\end{array}$ & $5 \mathrm{~L}$ & $20 \mathrm{~L}$ & $80 \mathrm{~L}$ & $80 \mathrm{~L}$ \\
\hline Manufacturer & $\begin{array}{c}\text { Apeks Supercritical } \\
\text { (Columbus, OH, } \\
\text { USA) }\end{array}$ & $\begin{array}{c}\text { Eden Labs } \\
\text { (Seattle, WA, } \\
\text { USA) }\end{array}$ & $\begin{array}{c}\text { ExtraktLAB } \\
\text { (St Croix Falls, WI, } \\
\text { USA) }\end{array}$ & $\begin{array}{l}\text { Apeks Supercritical } \\
\text { (Columbus, OH, } \\
\text { USA) }\end{array}$ \\
\hline $\begin{array}{c}\text { Temperature of } \\
\text { Extraction }\end{array}$ & $\operatorname{Max} 71^{\circ} \mathrm{C}$ & $-60^{\circ} \mathrm{C}-60^{\circ} \mathrm{C}$ & $25-100^{\circ} \mathrm{C}$ & $\operatorname{Max} 71^{\circ} \mathrm{C}$ \\
\hline Scale of Production & $\begin{array}{c}\text { Small Scale } \\
\text { Commercial, R\&D }\end{array}$ & Commercial & $\begin{array}{l}\text { Large Scale } \\
\text { Commercial, } \\
\text { Industrial }\end{array}$ & $\begin{array}{l}\text { Large Scale } \\
\text { Commercial, } \\
\text { Industrial }\end{array}$ \\
\hline
\end{tabular}




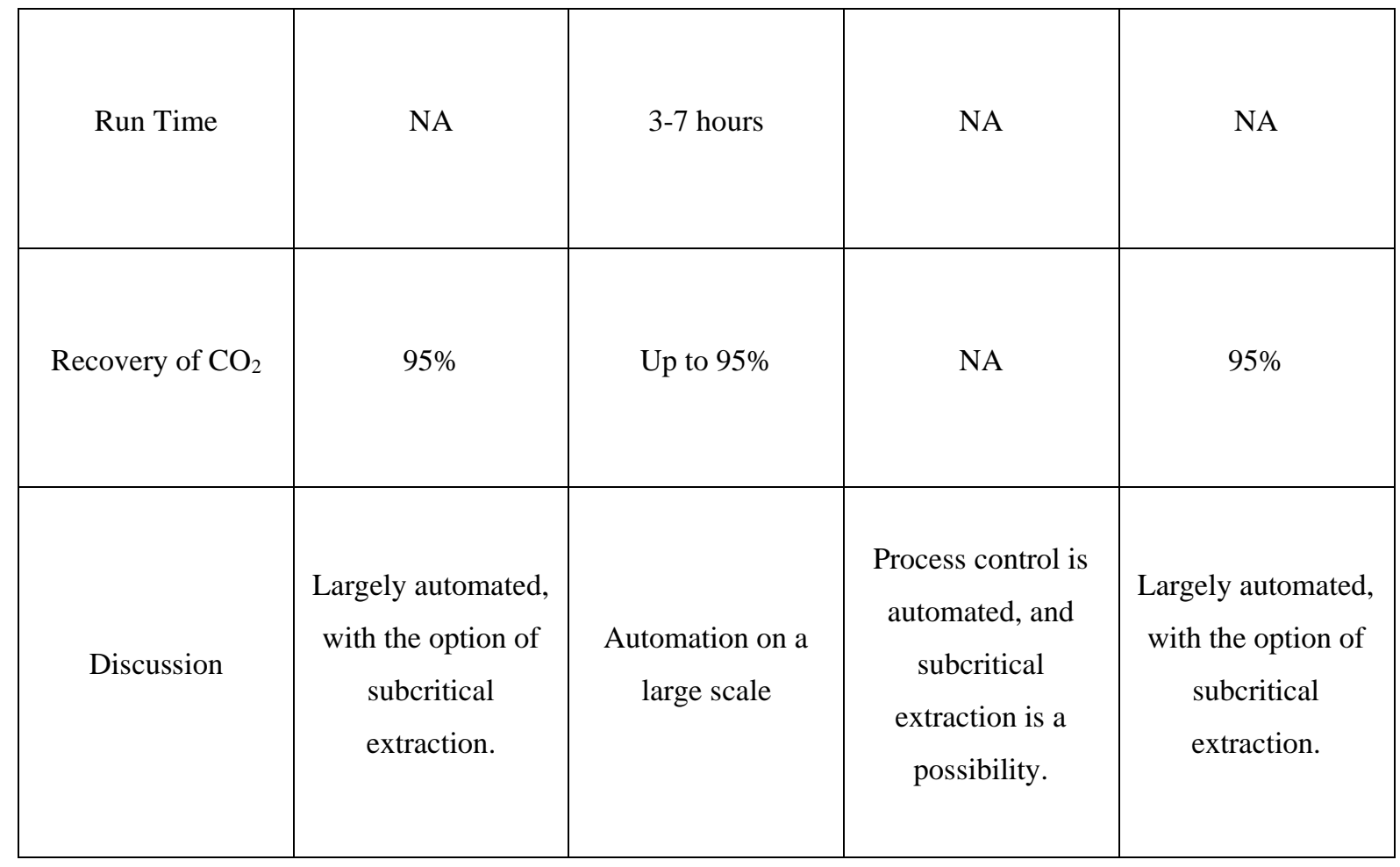

Table 4: Several SC-CO $\mathrm{CO}_{2}$ extraction sets of apparatus and their technical information for cannabis extraction.

Several parameters must be determined in order to design an SFE processor, including operating pressure and temperature, solvent flow (scale), solvent-to-feed ratio, recovery conditions (precipitation), solid matrix pre-treatment, initial moisture content, and other mass transfer parameters.

There is an obvious lack of quality research for formulating the $\mathrm{SC}-\mathrm{CO}_{2}$ extraction parameters because there are multiple parameters affecting process efficiency and different researchers have different interests and perceptions. However, a number of trends, including the optimal temperature for each set of extraction parameters, have been discovered experimentally through trial-and-error processes.

Different companies offer different $\mathrm{SC}-\mathrm{CO}_{2}$ extraction technologies due to high capital costs, safety concerns, and other technical considerations. Table 4 lists a variety of large-scale SC$\mathrm{CO}_{2}$ extraction systems, as well as their technical specifications. 
The supercritical extraction machines are usually automated, as shown in Table 4, allowing for lower labour costs and fewer safety concerns. However, the equipment is still costly enough to deter start-ups with insufficient funding, which is another reason why OSE (Organic Solvent Extraction) was chosen over $\mathrm{SC}-\mathrm{CO}_{2}$ extraction. The density of the inlet materials determines the processing capacity and thus yield. The operation parameters can be tweaked based on the properties of the inlet material as well as the desired product compositions.

Despite its high capital costs, SFE has been used to extract various chemicals from a variety of biomass species. Arranz et al., working on anti-inflammatory compounds, used supercritical carbon dioxide to extract terpenolic camphor, which accounted for more than $33 \%$ of the total extract, demonstrating the selective ability of $\mathrm{SC}-\mathrm{CO}_{2}$ 's toward terpenes.

\begin{tabular}{|c|c|c|c|}
\hline Form of Biomass & $\begin{array}{c}\text { Operating } \\
\text { Temperature \& } \\
\text { Pressure }\end{array}$ & Study Objective & Pre-Treatment \\
\hline Hemp Inflorescence & $10 \& 14 \mathrm{MPa}, 40^{\circ} \mathrm{C}$ & $\begin{array}{l}\text { Comparison of the } \\
\text { hydro-distillation } \\
\text { performance with the } \\
\text { recovery of volatile } \\
\text { chemicals from } \\
\text { inflorescences. }\end{array}$ & Ground \\
\hline Leaves \& Buds & $\begin{array}{c}17,24 \& 34 \mathrm{MPa} \text { at } \\
55^{\circ} \mathrm{C} \mathrm{CO}_{2} \text { flow rate of } \\
200 \mathrm{~g} \mathrm{~min}^{-1}\end{array}$ & $\begin{array}{l}\text { The effects of pressure, } \\
\text { cannabis plant } \\
\text { composition at the start, } \\
\text { time, and the use of } \\
\text { ethanol as a co-solvent } \\
\text { are all being } \\
\text { investigated. }\end{array}$ & Ground \\
\hline Hemp Inflorescence & $25 \mathrm{MPa}, 60^{\circ} \mathrm{C}$ & $\begin{array}{c}\text { Proposing a technique } \\
\text { for extracting CBD- and } \\
\text { THC-rich cannabis plant } \\
\text { components }\end{array}$ & Ground \\
\hline
\end{tabular}




\begin{tabular}{|c|c|c|c|}
\hline Hemp Flower & $\begin{array}{c}42,54,61 \& 72^{\circ} \mathrm{C} ; 13.2- \\
25.1 \mathrm{MPa}\end{array}$ & $\begin{array}{l}\text { Analytical techniques for } \\
\text { determining cannabinoid } \\
\text { solubility }\end{array}$ & NA \\
\hline Hemp Flower & $\begin{array}{c}42,53, \& 61^{\circ} \mathrm{C} ; 11.3- \\
20.6 \mathrm{MPa}\end{array}$ & $\begin{array}{c}\text { The solubility of } \\
\text { psychoactive and non- } \\
\text { psychoactive substances } \\
\text { is compared. }\end{array}$ & NA \\
\hline Hemp & $110-140$ bar, $40-60^{\circ} \mathrm{C}$ & $\begin{array}{l}\text { In } \mathrm{SC}_{-\mathrm{CO}_{2}} \text {, the molar } \\
\text { solubility of several } \\
\text { cannabinoids was } \\
\text { compared. }\end{array}$ & NA \\
\hline Hemp & $60 \mathrm{MPa} ; 35^{\circ} \mathrm{C}$ & $\begin{array}{l}\text { The process of } \\
\text { extracting a herbal } \\
\text { medicine from medical } \\
\text { cannabis. }\end{array}$ & Ground \\
\hline
\end{tabular}

Table 5: Cannabinoid extraction with $\mathrm{SC}-\mathrm{CO}_{2}$ has been studied in the past.

A number of recent studies on $\mathrm{SC}-\mathrm{CO}_{2}$ processing of medical cannabinoids are summarised in Table 5. SC- $\mathrm{CO}_{2}$ also has a lot of promise in terms of fatty-acid extraction (Table 6). PerrotinBrunel et al. (2010) proposed thermodynamic models to depict the mutual behaviour of cannabinoid blends in order to correlate the parameters with the results.

However, based on what is available in the literature and in industry, $\mathrm{SC}-\mathrm{CO}_{2}$ is a wellestablished method for extracting higher-value chemicals, with insufficient formulation and scaling protocols, to the point where trial-and-error procedures are still considered the only way to improve the process. Subcritical $\mathrm{CO}_{2}$ has also proven to be a viable option for cannabinoid extraction, in addition to supercritical $\mathrm{CO}_{2}$. 
For example, B. A. Whittle et al. (2020) revealed the details of an invention that used $\mathrm{CO}_{2}$ at $10 \pm 5{ }^{\circ} \mathrm{C}$ under a pressure of $60 \pm 10$ bar (subcritical $\mathrm{CO}_{2}$ ) to extract the main cannabinoids efficiently.

\section{Organic Solvent Extraction vs. Supercritical Fluid Extraction $\left(\mathrm{SC}-\mathrm{CO}_{2}\right)$ for Extraction of Cannabinoids: Extraction Potential, Solubility Sphere, Solubility Parameter ( $\delta$-values), Alcohol on Solubility of Cannabinoids, Extraction Yields}

According to the SPT (Solubility Parameter)theory, $\mathrm{SC}-\mathrm{CO}_{2}$ has a medium to low extraction potential in terms of cannabinoids and terpene solubility. Ethanol, on the other hand, has a larger solubility sphere and thus a wider solubility range. On the negative side, ethanol extraction is followed by winterization, which occurs when the solubility of cannabinoids and terpenes decreases as the temperature drops, resulting in partial sedimentation of cannabinoids and terpenes as well as extraneous compounds.

\begin{tabular}{|c|c|c|c|}
\hline Biomass & Parameters & Study Objective & Pre-Treatment \\
\hline Hempseed & $\begin{array}{c}40-80^{\circ} \mathrm{C} \text { pressures of } 20- \\
40 \mathrm{MPa} \mathrm{CO}_{2} \text { flow rate } 3 \\
\mathrm{~mL} \mathrm{~min}^{-1}\end{array}$ & $\begin{array}{l}\text { Calculate the amount of } \\
\text { fatty acids, tocopherols, } \\
\text { and pigments } \\
\text { (chlorophyll a and b and } \\
\text { total carotene). }\end{array}$ & $\begin{array}{c}\text { Desiccate Ground } \\
\text { Hempseed Sieved (24- } \\
\text { Mesh Tray) }\end{array}$ \\
\hline Hempseed & $\begin{array}{c}\text { Temperature }(40,50 \& \\
\left.60^{\circ} \mathrm{C}\right), \text { Pressure }(250, \\
300 \& 350 \text { bar }) \& \\
\text { Particle Diameter }(0.59, \\
0.71 \& 0.83 \mathrm{~mm})\end{array}$ & $\begin{array}{c}\text { Stability of total } \\
\text { extraction and oxidation }\end{array}$ & $\begin{array}{c}\text { Ground for } 10,30 \& 60 \\
\text { seconds }\end{array}$ \\
\hline
\end{tabular}




\begin{tabular}{|c|c|c|c|}
\hline Hemp Stem Fibre & $\begin{array}{c}35 \mathrm{MPa} \& 50^{\circ} \mathrm{C}(40 \\
\mathrm{MPa} \& 65^{\circ} \mathrm{C}, \text { maximum } \\
\text { crude wax extraction } \\
\text { yield })\end{array}$ & $\begin{array}{l}\text { Fatty acids, policosanols } \\
\text { (fatty alcohols), fatty } \\
\text { aldehydes, triterpenoids, } \\
\text { hydrocarbons, sterols, } \\
\text { and cannabinoids are } \\
\text { among the compounds } \\
\text { extracted. }\end{array}$ & Fine Powder \\
\hline Hempseed & $\begin{array}{l}\text { Temperatures of } 40,60 \\
\& 80^{\circ} \mathrm{C} \& \text { Pressures of } \\
300 \& 400 \mathrm{MPa}\end{array}$ & $\begin{array}{l}\text { Extraction yields, fatty } \\
\text { acid makeup of the oil, } \\
\text { and oxidation stability } \\
\text { are all factors to } \\
\text { consider. }\end{array}$ & Finely Ground \\
\hline $\begin{array}{c}\text { There are } 51 \text { distinct } \\
\text { hemp genotypes. }\end{array}$ & $\begin{array}{c}\text { Extraction that } \\
\text { has optimised } \\
\text { temperature, controlled } \\
\text { heating at } 40^{\circ} \mathrm{C} \text {, and a } \\
\text { total volume of } \\
\text { parameters were: } 51.7 \\
\mathrm{MPa}, 100^{\circ} \mathrm{C} \text { extraction } \\
\text { temperature, and } 120 \mathrm{~mL} \\
\mathrm{CO}_{2} \text { per extraction. }\end{array}$ & $\begin{array}{l}\text { Composition of fatty } \\
\text { acids and tocopherol } \\
\text { content }\end{array}$ & Finely Ground \\
\hline Hempseed & $\begin{array}{l}\text { With a } \mathrm{CO}_{2} \text { mass flow } \\
\text { rate of } 4.9 \mathrm{~kg} \mathrm{~h}^{-1} \text { and a } \\
\text { pressure of } 20 \mathrm{MPa} \text { and } \\
\text { a temperature of } 40^{\circ} \mathrm{C} \text {, }\end{array}$ & $\begin{array}{l}\text { Examine the effect of } \\
\text { extraction conditions on } \\
\text { tocopherol, fatty acid, } \\
\text { and pigment } \\
\text { concentrations. }\end{array}$ & Pressed \\
\hline
\end{tabular}

Table 6: Research on $\mathrm{SC}-\mathrm{CO}_{2}$ extraction of fatty acids have been published.

Figure 4 depicts the approximate solubility parameter values for cannabinoids, terpenes, coextracted waxes, ethanol, and $\mathrm{SC}-\mathrm{CO}_{2}$ for cannabinoids, terpenes, and co-extracted waxes. It 
is important to note that the solubility parameter ( $\delta$-values) is a known constant value for a pure substance in a specific physical state. For example, at $-10{ }^{\circ} \mathrm{C}$, liquid $\mathrm{CO}_{2}$ has a $\delta$-value of about 17.5, but for $\mathrm{SC}-\mathrm{CO}_{2}$ and organic solvents, this number varies in the form of $\mathrm{f}$ (temperature, pressure).

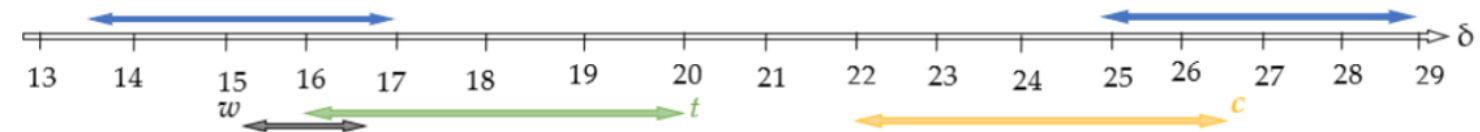

Figure 4: $\delta$-values $\left(\mathrm{MPa}^{0.5}\right)$ of SC-CO 2 (top-left), ethanol (top-right), cannabinoids (c), terpenes $(\mathrm{t})$, and waxes (w) (Approximately)

The $\delta$-value of ethanol swings toward 29 during winterization, putting $(\Delta \delta)$ the solubility status outside the solubility sphere, indicating that the wax is no longer dissolved in the media. Alcohols, on the other hand, increase the solubility of cannabinoids in $\mathrm{SC}-\mathrm{CO}_{2}$ (co-solvent), lowering the SC-CO $\mathrm{CO}_{2}$ flow required for extraction. J.W. King (2019) investigated the solubility parameters in cannabinoid extraction in depth.

Experiment results back up the predictions of the SPT (Solubility Parameter) theory. Whittle B. et al. (2008) proposed a method for precipitating a significant portion of undesirable waxy materials from cannabis extracts dissolved in $\mathrm{C} 1-\mathrm{C} 5$ alcohols and stored in chilled environments for long periods of time. Rosenthal (2014) describes the dewaxing process in detail by programming the temperature change in a similar study.

Attard et al. found that $\mathrm{SC}-\mathrm{CO}_{2}$ was superior to heptane's Soxhlet in extracting hemp dust; samples yielded significant amounts of high-value lipophilic molecules such as fatty acids, policosanols (fatty alcohols), fatty aldehydes, hydrocarbons, sterols, triterpenoids, and cannabinoids (CBD: $5832 \mu \mathrm{g} / \mathrm{g}$ of dust). For the majority of compounds, they discovered that $35 \mathrm{MPa}$ and $50{ }^{\circ} \mathrm{C}$ was the best combination for getting the best extraction yield.

\subsection{Efficient Mass Transfer through Pre-Treatment Methodologies}


Pre-treatment methods are categorised according to how they contribute to efficient mass transfer. High-pressure homogenization, press, ultrasonication, microwave, acids lysing, enzymes, and osmotic shocks are some of these methods.

\subsubsection{Preparing the Hemp Seed for Oil Extraction through Mechanical Extraction: Screw} Extruder, Pressurised Liquid Extractor (PLE), Cold-Pressing, Ease of Extraction of Undesirable Constituents from the Inner Tissue Matrix through Grinding the Biomass \&

\section{Complicated Downstream Purification}

Mechanical extraction is primarily used to prepare the hempseed for oil extraction. Hempseeds go through a drying process that reduces their moisture content to $10 \%$ or less to prevent sprouting. The physically extractable fatty acids are then removed from dry seeds using screw expellers or pressing instruments. Following that, the solvent is added to the pressed biomass in order to dissolve and remove any remaining oil.

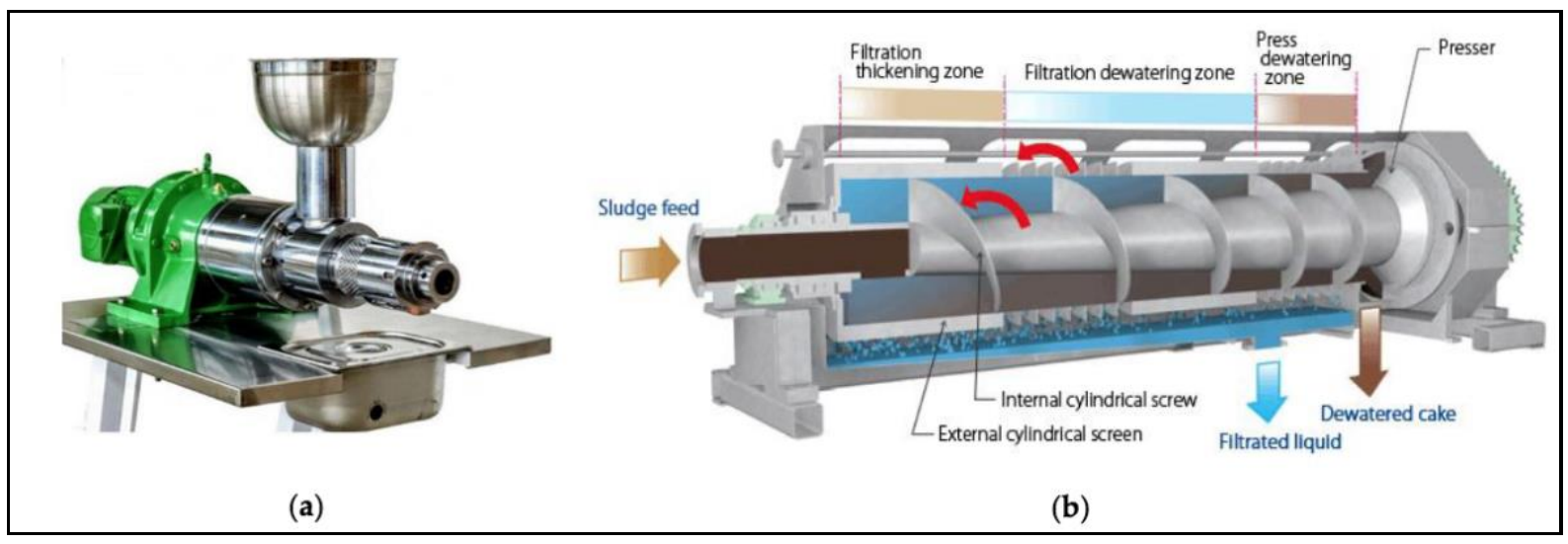

Figure 5: Screw expellers (a) feed from the top and (b) feed from the front are two typical types of screw expellers used for cold pressing hemp.

Extraction of hempseed oil, proteins, and other nutritional by-products has been found to be low-cost using a screw extruder or a pressurised liquid extractor (PLE). This process can be done at room temperature (cold press) or at higher temperatures (heated press).

Cold pressing is a low-cost, slow process that protects the quality of heat-sensitive chemical compounds. Because they do not require any prior preparation, screw expellers (Figure 5) are 
generally faster and less expensive. However, this method generates a large amount of waste, including peels, seeds, defatted oilseed meals, and oil sludge, which must be processed further.

The screw-expelling or pressing method of extracting cannabinoids and terpenes is ineffective because the majority of cannabinoids accumulate on the surface of flower trichomes. In fact, grinding the biomass to a fine powder aids in the extraction of undesirable constituents from the inner tissue matrix, necessitating complicated downstream purification. However, prior to extraction, mild shredding or crushing of the flowers can help reduce solvent consumption.

\subsubsection{Enabling Mass Transfer by Expanding the Biomass Matrix, Producing Heat} through Microwave-assisted Extraction Pre-Treatment: Solvent polarity, Extraction Duration, Irradiation power, Temperature, and Contact Surface Area, Relation b/w Extraction Yield \& Oxidative Stability, Risk of Mechanical Energy Conversion \& Decarboxylation of Cannabinoids

Microwave-assisted extraction (MAE) is a molecular-level mechanical pre-treatment in which waves enter the plant tissue, are absorbed, produce heat, expand the biomass matrix, and disintegrate it, enabling mass transfer. This approach is quicker and has been proven to be a potent alternative to standard OSE (Organic Solvent Extraction) or $\mathrm{SC}_{-} \mathrm{CO}_{2}$ (Supercritical Fluid Extraction) procedures, as it does not require the biomass to be dried.

\begin{tabular}{|c|c|c|c|}
\hline $\begin{array}{c}\text { Method of Pre- } \\
\text { Treatment }\end{array}$ & $\begin{array}{c}\text { Flower vs. Seed } \\
\text { (Cannabinoids vs. } \\
\text { Lipids) }\end{array}$ & Proper Scale & Discussion \\
\hline Ultrasonication & Both & Small & Fast, Expensive \\
\hline Press \& Screw Expeller & Fatty-Acid & Small \& Large & Slow \& Cheap \\
\hline Microwave & Fatty-Acid & Small \& Large & Fast, Cheap \\
\hline
\end{tabular}




\begin{tabular}{|c|c|c|c|}
\hline Grind & Both & Small \& Large & Fast \& Cheap \\
\hline $\begin{array}{c}\text { High-Pressure } \\
\text { Homogenization }\end{array}$ & Both & Small & Fast \\
\hline
\end{tabular}

Table 7: Methods of pre-treatment classification

Solvent polarity, extraction duration, irradiation power, temperature, and contact surface area are the important factors to modify, and most lab-scale research has focused on parameter optimization. Rezvankhah A. et al. (2019), for example, did optimization research on the extraction of fatty acids from hemp seed oil and were able to get almost 34 weight $\%$ at the optimal point of $450 \mathrm{~W}$ and 7 minutes. When the authors compared their results to Soxhlet's, they discovered that Soxhlet had a greater oil extraction yield $(37.93 \% \mathrm{w} / \mathrm{w})$ but a worse oil oxidation stability.

Table 7 summarises the classification of several pre-treatment techniques for cannabinoids, terpenes, and fatty acids extraction. By facilitating the mass transfer rate, virtually all mechanical pre-treatment techniques, whether macro-scale (grinding) or micro-scale (ultrasonic), enhance extraction yield and minimise operating time. However, the mechanical energy used in the system eventually converts to thermal energy, which can lead to transformation; as a result, caution must be exercised while extracting cannabinoids from hemp seeds, since the produced heat has the potential to decarboxylate the natural cannabinoids.

\subsubsection{Extraction from Hemp through Pressurised Hot Water in Supercritical State on Biomass Samples: Extraction of Less-Psychoactive Compounds}

In addition to the traditional OSE (Organic Solvent Extraction) and SFE (Supercritical Fluid Extraction) processes, novel "green" technologies to extracting various compounds from hemp have been developed and implemented. On various biomass samples, pressurised hot water in its supercritical state was used as a solvent and shown to have similar solvability qualities to methanol and ethanol. 
Nuapia Y. et al. (2020) used the pressurised hot water extraction (PHWE) approach to extract THC, CBN, CBD, CBG, and CBC components from hempseed in a recent optimization research. When comparing the findings of their extraction to those of previous techniques, they stated that their approach is quicker and more selective in extracting less-psychoactive components. On the negative, comparing the critical temperature and pressure of $\mathrm{CO}_{2}\left(31^{\circ} \mathrm{C}\right.$, 73 bars) to that of water $\left(374^{\circ} \mathrm{C}, 217\right.$ bars $)$ plainly indicates that supercritical water is expensive and potentially dangerous.

\section{Concentration of THC presence in the Form of Carboxylic Acid Precursor in Plants: Decomposition of THC-acid (THCA) through Decarboxylation, Desiccation Settings, Quantitative Underestimation of conversion of THCA to THC}

Because of the unfavourable psychoactive effects in the United States and other areas of the world, THC concentration has long been a point of contention. During the preparation of the plant or extracts, this amount fluctuates. The neutral cannabinoids (THC, etc.) do not occur in substantial amounts in plants, as previously stated; instead, they are present in the form of their carboxylic acidic precursor.

This transition occurs when THC-acid (THCA) is decomposed into neutral THC and $\mathrm{CO}_{2}$ is released in a process termed decarboxylation (Scheme 1), in which it loses $12 \%$ of its mass. Several investigations have shown that decarboxylation follows a first-order kinetic model in which the rate constant is influenced by the prevailing driving factor.

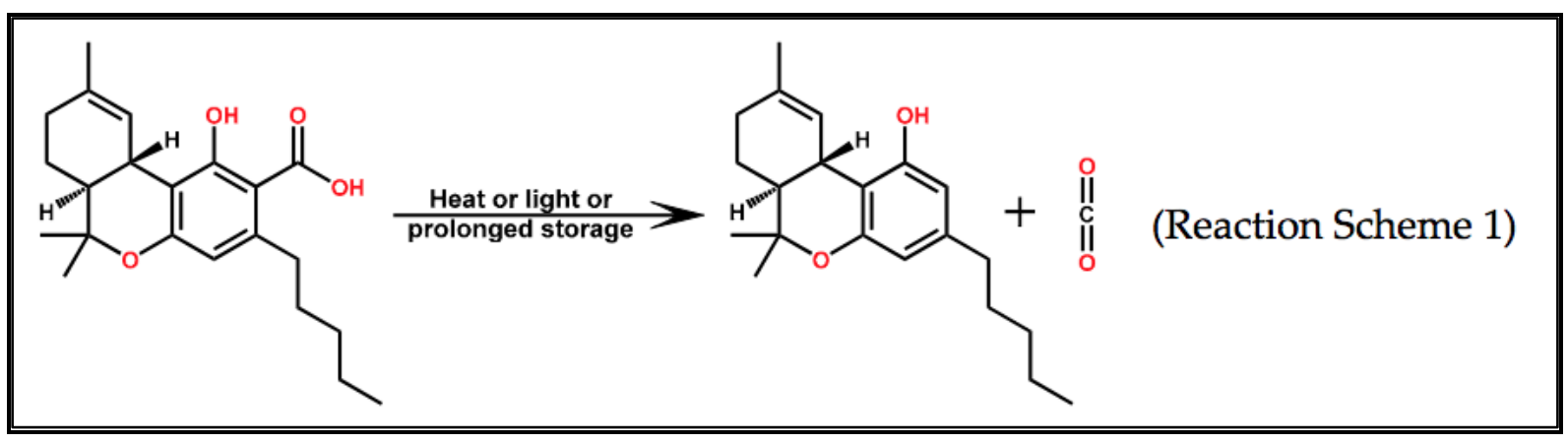

Scheme 1 
Desiccation settings, including temperature, electron-beam irradiation, length of processing, storage conditions, extraction technique, and other applications requiring chemical evolution, have all been examined. Due to the well-known Le Chatelier's principle, the decarboxylation reaction (reaction scheme 1) continues with a drop in pressure and an increase in temperature. As a result, the amount of THC produced during extraction and low-pressure distillation increases dramatically (purification).

To determine total THC concentration, most food and drug companies employ the cautious method "Total THC = THCA + THC." This kinetic model, on the other hand, is unrealistic and is a source of debate among lawmakers in the United States. Dussy F.E. et al. (2004) studied the rise in THC concentration when smoking in simulation research and discovered that only $30 \%$ of THCA converts into psychoactive THC while smoking.

According to Iffland et al. (2016), the conversion of THCA to THC is frequently underestimated by up to $50 \%$ higher than the real THC level because the decarboxylation reaction seldom completes. They came to the conclusion that the quantity was calculated incorrectly and does not reflect the true amount of psychoactive components.

6.1 Effects of Light on Cannabis Photobiology with Post-Harvest Cannabis Profile Change: Chromophores, Photo-Excitation of Molecules by Absorption of Light, Photophysical \& Chemical Changes due to Vibrational \& Rotational Movements, Decarboxylation in the Presence of Light, Effect of Light on Decomposition's Kinetics \&. Stoichiometry, Radical-Scavenging Capabilities of Hydroxyl Groups as a result of UV Absorption during Advanced Oxidation Processes (AOP) 


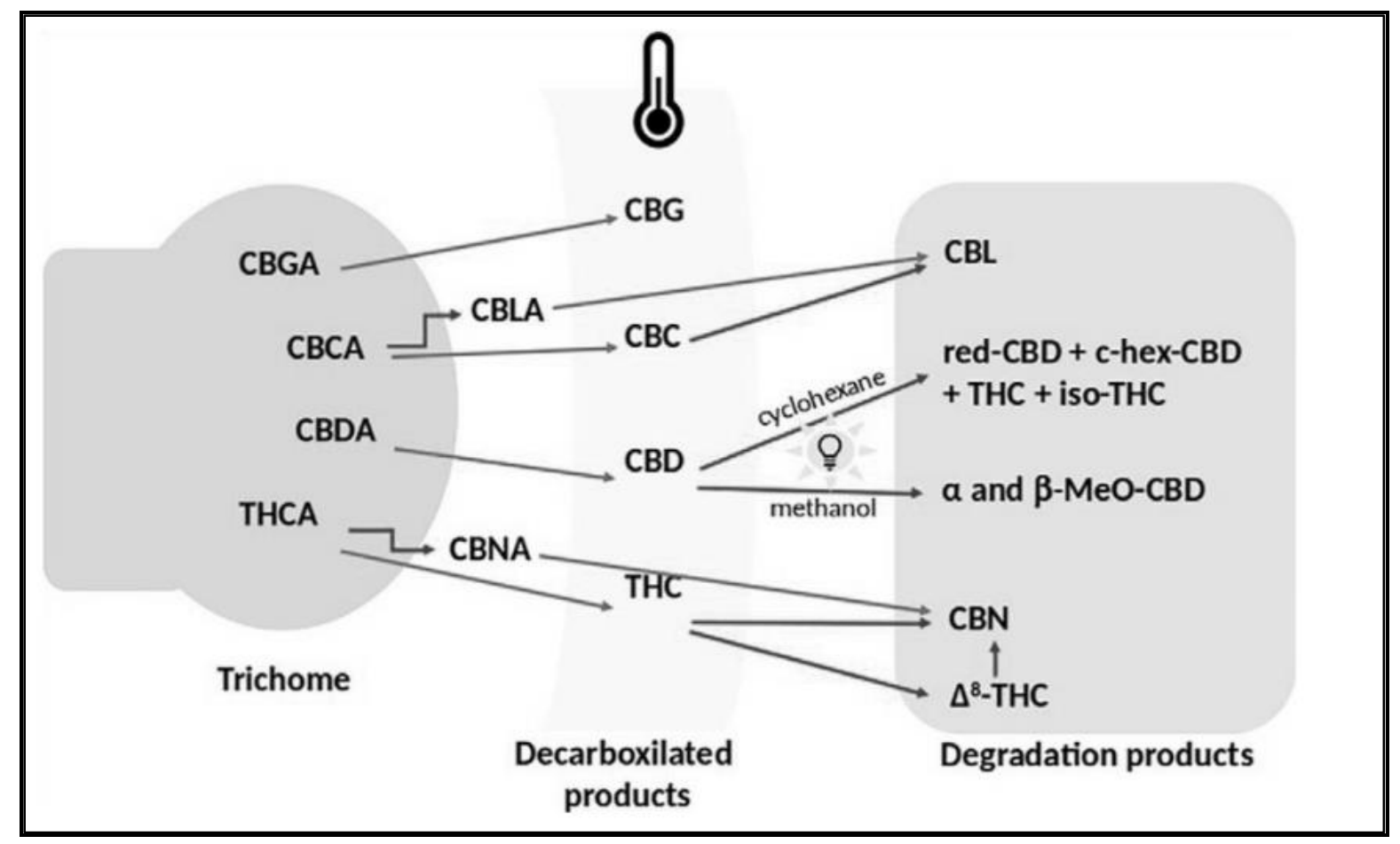

Figure 6: Decarboxylation connects the major components of hemp.

Many studies have focused on the effects of light on cannabis photobiology; nevertheless, there are just a few published publications that look at the post-harvest cannabis profile change produced by light.

Cannabinoids include a variety of functional groups, including carbon-carbon double bonds and aromatic moieties, which interact with light and are known as chromophores. The absorption of light, which photo-excites the molecules, is involved in this interaction.

The molecules' total energy level rises as a result of light absorption, putting them in a photoexcited state with increased vibrational and rotational movements that allow photophysical and chemical changes. Although light absorption can cause reversible photophysical transformations such as photoisomerization, we will focus on irreversible chemical changes such as decarboxylation in the presence of light.

Zamengo et al. (2019) discovered that, despite substantial drops in CBDA, the CBD concentration remained consistent over time under varied storage settings in four-year research. 
They discovered that the presence of light had a substantial beneficial impact on the decomposition's kinetics and stoichiometry.

Trofin et al. compared darkness to natural light exposure at 4 and $22^{\circ} \mathrm{C}$ over a four-year period and found that light-induced substantial THC breakdown. Both investigations found that CBN and THC levels follow an exponential pattern in the opposite direction, plateauing between 800 and 1200 days, with CBN forming as THC declines. Ramirez et al. (2018) did a detailed analysis and identified probable mechanisms for carboxylic cannabinoids to undergo natural, thermal, and photochemical transformations during inflorescence (Figure 6). As seen in Figure 6, greater temperatures decarboxylate all acid cannabinoids, which can then be degraded further into breakdown products, as previously demonstrated by other studies.

Fairbrain et al., on the other hand, reported no CBN transformation accompanied by lightinduced THC degradation, while finding that lighting had the greatest influence on THC level when compared to air-oxidation and temperature variations. Park et al. (2018) used a mediumpressure polychromatic UV lamp (200-300 nm) to study direct UV photolysis and $\mathrm{UV} / \mathrm{H}_{2} \mathrm{O}_{2}$ photobleaching processes on the photodegradation/oxidation of THCA and discovered that both the direct $\mathrm{UV}$ photolysis and the $\mathrm{UV} / \mathrm{H}_{2} \mathrm{O}_{2}$ (increased acidity) photobleaching processes followed pseudo-first-order kinetics. Even while reducing $\mathrm{pH}$ alone did not result in THCA breakdown in this study, the addition of acidic agents under UV light had a considerable impact. This is due to the radical-scavenging capabilities of hydroxyl groups as a result of UV absorption during advanced oxidation processes (AOP).

\section{Eliminating Undesirable Components from Extract such as THC \& residual Chlorophyll while increasing Cannabidiol Strength through Purification: Creation of Isolates through Crystallization or Chromatography}

The oil still includes numerous other components after the initial extraction, in addition to CBD. Purification aims to eliminate undesirable components from the extract, such as THC and residual chlorophyll, while also increasing the CBD strength of the finished product. Distillates can have up to $90 \%$ cannabis content, and they can be used to make edibles, topicals, 
and vape products, among other things. Crystallization or chromatographic methods can be used to create isolates.

Figure 7 is an example of secondary processing processes that may be used to create specific products. CBD isolate is made by dissolving high purity oil (ideally at least 70\%) in a solvent and crystallising it. Pentane is a frequent choice, although other organic solvents, such as C48 alkanes or alkyl alcohols, can also be employed. The solvent is heated to $30-45^{\circ} \mathrm{C}$ before adding the CBD oil. To encourage crystallisation, the mixture is cooled to $20-10^{\circ} \mathrm{C}$ for at least 12 hours after the oil has entirely dissolved. Once enough crystals have been produced, they can be filtered and washed with cold solvent to remove residue and enhance colour. To increase yield, the filtrate can be collected and treated.

The CBD crystals can be dried, ground then dried again using a rotary evaporator, for example. The CBD content of the isolate can be as high as $95-99.8 \%$ by weight of dry matter using this technique. When industrial hemp is utilised, the THC concentration is $00.5 \%$. Crystallization is a feasible process for producing CBD isolation, but time-consuming and labour-intensive.

\subsection{Separating a Homogeneous Liquid Mixture into its constituents through Distillation: Creation of Vapeables, Topicals \& Edibles through Distillates, Short-Path Distillation \& Wiped Film Distillation, Increasing the Mass Transfer Rate through Agitation by Wipers}

distillate is viscous, the additional agitation provided by the wipers increases the mass transfer rate and therefore speeds up the distillation process.

Distillation is a vapour-phase separation method for separating a homogenous liquid mixture into its constituents. When the combination is heated, it separates into two phases: gas and liquid. More volatile components pass into the gas phase, where they may be separated and condensed to obtain the distillate. In layman's terms, this implies that the component with the lower boiling point (BP) evaporates first and is moved to the gas phase.

THC and CBD have BPs that are quite near to each other $\left(160-180^{\circ} \mathrm{C}\right.$ and $157^{\circ} \mathrm{C}$, respectively), making full removal of THC difficult and inefficient. 
Distillates may be used to make a variety of goods, including vapeables, topicals, and edibles, as illustrated in Figure 7. Distillation may eliminate any variation between products generated from various plant strains, thus terpenes are commonly reintroduced back into the distillates.

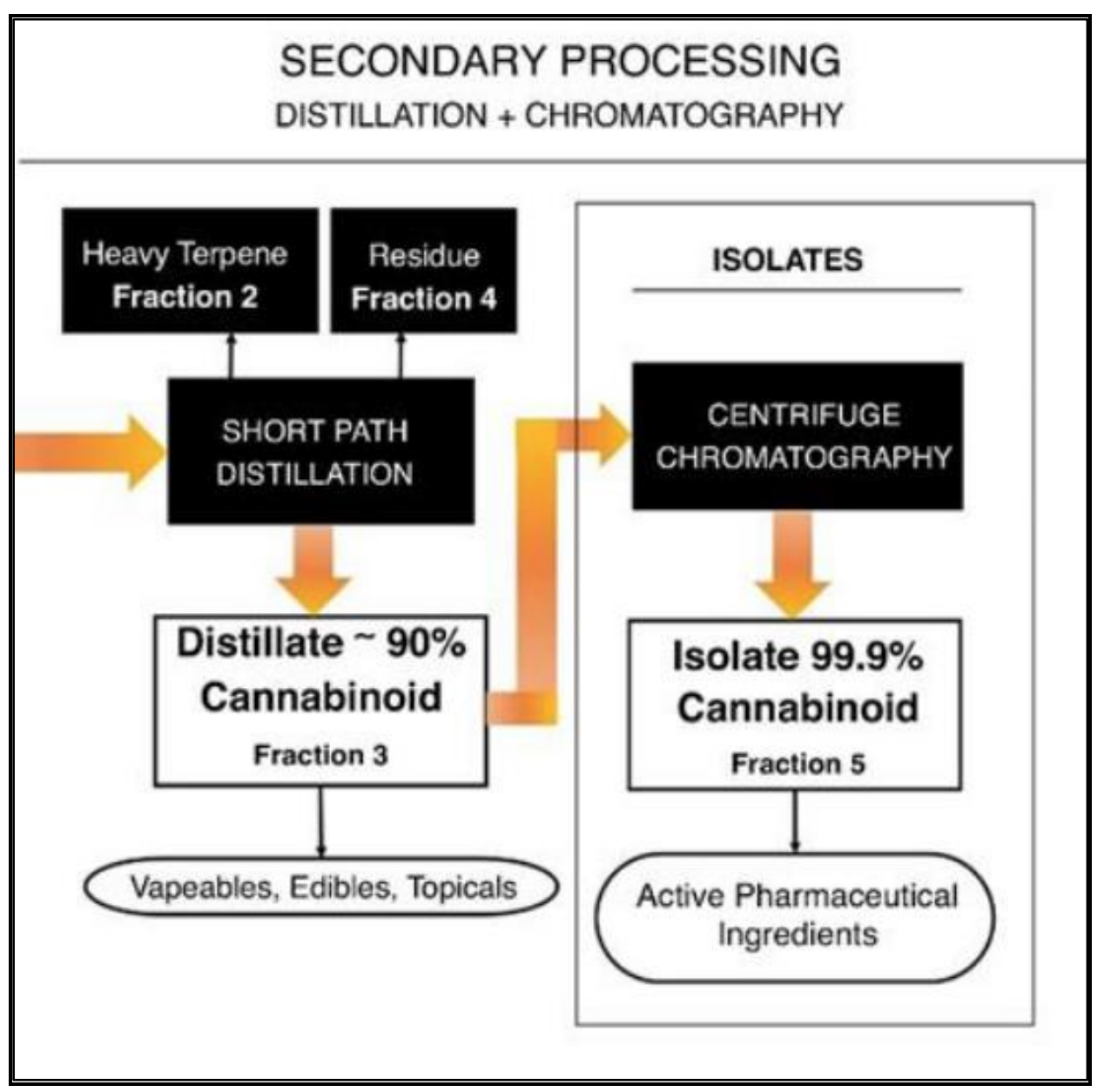

Figure 7: Secondary processing stages, distillation, and centrifugal chromatography are all employed in the production of several commercial marijuana products.

Short-path distillation and wiped film distillation are the two most popular distillation processes used to make cannabis and hemp products. Distillation is usually done at a low pressure since high temperatures might cause the cannabinoids to degrade.

The mixture is heated in a flask under vacuum in short-path distillation. The vapour travels just a short distance before being cooled and collected in a condenser. Because this approach is extremely successful and the equipment required is relatively tiny, it is frequently utilised by smaller-scale operations. The initial mixture is delivered into the machine from above, and 
wiper blades spread it across the surface of a heated tube in wiped film distillation. To properly remove an undesirable components from the product, both wiped film and short-path distillation generally require at least two passes.

The basic principle of wiped film distillation is depicted in Figure 8. The feed is fed into the evaporator, where the wiper blades distribute it across the walls. Terpenes that are very volatile vaporise quickly and can be condensed and collected individually. The next portion to vaporise is cannabinoids. The internal condenser condenses them and collects them at the bottom. The heavier fractions, such as chlorophyll and residual wax, are recovered from the evaporator's outer surface.

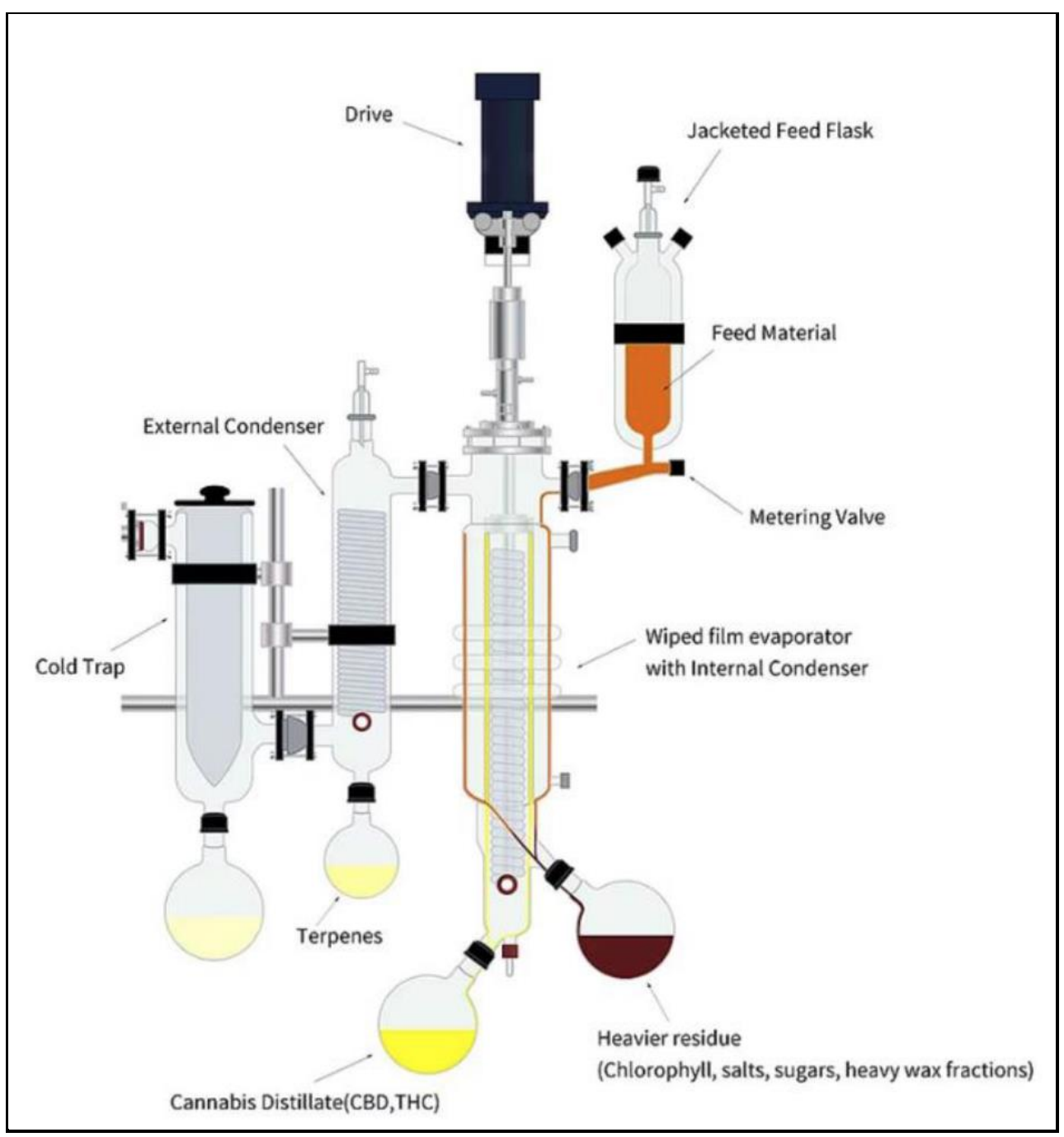

Figure 8: Representation of Wiped-Film Distillation 
Because the distillate is viscous, the additional agitation provided by the wipers increases the mass transfer rate and therefore speeds up the distillation process.

\begin{tabular}{|c|c|c|}
\hline Name of Product & KD-30 & clearSTILL \\
\hline Method of Distillation & $\begin{array}{c}\text { Short Path Distillation, 1-3 Stages } \\
\text { Available }\end{array}$ & 2-stage wiped film distillation \\
\hline Heating Range of the Evaporator & $25-300^{\circ} \mathrm{C}$ & $38-206^{\circ} \mathrm{C}$ \\
\hline Manufacturer & Spectrum Technology & extraktLAB \\
\hline Production Scale & $\begin{array}{l}\text { Industrial Production on a } \\
\text { Medium to Large Scale }\end{array}$ & Commercial \\
\hline Capacity of Processing & $15 \mathrm{~L} / \mathrm{h}$ & 4-6 L/h \\
\hline Area of Evaporation & $0.30 \mathrm{~m}^{2}$ & $0.18 \mathrm{~m}^{2}$ \\
\hline
\end{tabular}

Table 8: Technical data about a variety of distillation equipment now on the market.

Table 8 shows various instances of distillation equipment that may be compared. There is no shortage of suitable equipment; these two examples were chosen since they are particularly marketed for the cannabis sector.

Table 8 shows two types of distillation equipment that can handle huge volumes of winterized oil. Because CBD oil distillation typically needs at least two passes, both types of equipment 
may perform at least two passes in a single cycle. This may reduce total processing time; however, systems that can only make one pass should be cleaned before making subsequent passes to avoid contamination.

\subsection{Immobilising the Stationary Phase \& Pushing the Mobile Phase at High Flow Rates through Counter-Current Liquid-Liquid Partitioning of Centrifugal Partition Chromatography: Partition Coefficients $\left(K_{d}\right)$, Overcoming the Challenge of Replacing Columns unlike HPLC or FC through Silica-absent Columns in CPC}

Centrifugal partition chromatography (CPC) is a counter-current liquid-liquid partitioning chromatography technique in which both the mobile and stationary phases are immiscible liquids. Centrifugal force immobilises the stationary phase, while the mobile phase is pushed through at high flow rates. Components are separated based on their partition coefficients $\mathrm{K}_{\mathrm{d}}$ and are partitioned between the stationary and mobile phases.

$\mathrm{K}_{\mathrm{d}}$ should be between 0.5 and 5 . The analyte is maintained in the mobile phase and no separation occurs if the value is less than 0.5 , and the analyte is retained in the stationary phase if the value is more than 5 .

The centrifugal force is generated by a column made up of discs linked to a rotor at the centre. The discs contain rotating seals on both ends, as well as over a thousand cells linked by a narrow channel that allows the mobile phase to pass through. To change the direction of the flow, a valve is needed. This permits the system to operate in either ascending or descending mode, with the stationary phase being the lighter liquid and the mobile phase being the heavier liquid in the descending mode.

$$
K_{d}=\frac{[A]_{\text {stat }}}{[A]_{\text {mob }}}
$$

$$
\begin{gathered}
\text { Where }[A]_{\text {stat }} \text { : concentration of } A \text { in the stationary phase } \\
{[A]_{\text {mob }}: \text { concentration of } A \text { in the mobile phase }}
\end{gathered}
$$

The lighter fluid is the mobile phase in ascending mode, whereas the heavier fluid is the stationary phase. Figure 9 demonstrates this notion. Figures 10 and 11 show how the discs are 
loaded into the computer. The cells are put on the discs and packed on the centre axis, which is linked to the rotating seals, as shown in Figure 10.

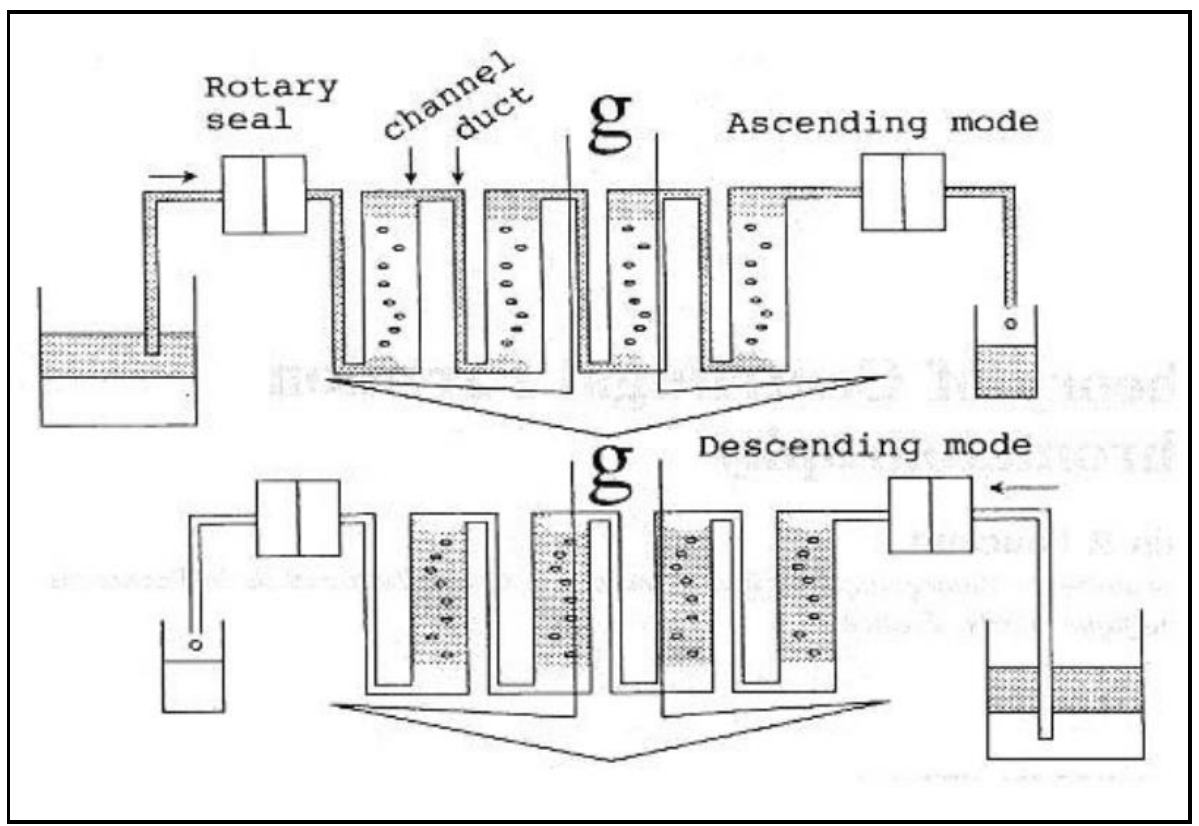

Figure 9: Concept of centrifugal partition chromatography.

The purification process can be carried out with a variety of liquids. The toxicity of the liquids is taken into account; for example, hexane, a widely used solvent, is known to be a neurotoxin, whereas other alternatives may be less harmful if consumed.

There is evidence that the product's purity is quite high, between 70 and $99 \%$, once the solvent is removed, implying that the amount of residual solvent is minimal. Some CPC systems have a run-time of fewer than 20 minutes and can process up to $90 \mathrm{~g}$ of crude oil per hour.

When opposed to High-Performance Liquid Chromatography (HPLC) and Flash Chromatography, one advantage of CPC (Centrifugal Partition Chromatography) is that the columns do not need to be changed because they do not include silica. For example, provided enough crude extract is available, a large industrial scale CPC system built by RotaChrom Technologies may theoretically generate up to $8 \mathrm{~kg}$ of pure CBD per week. 


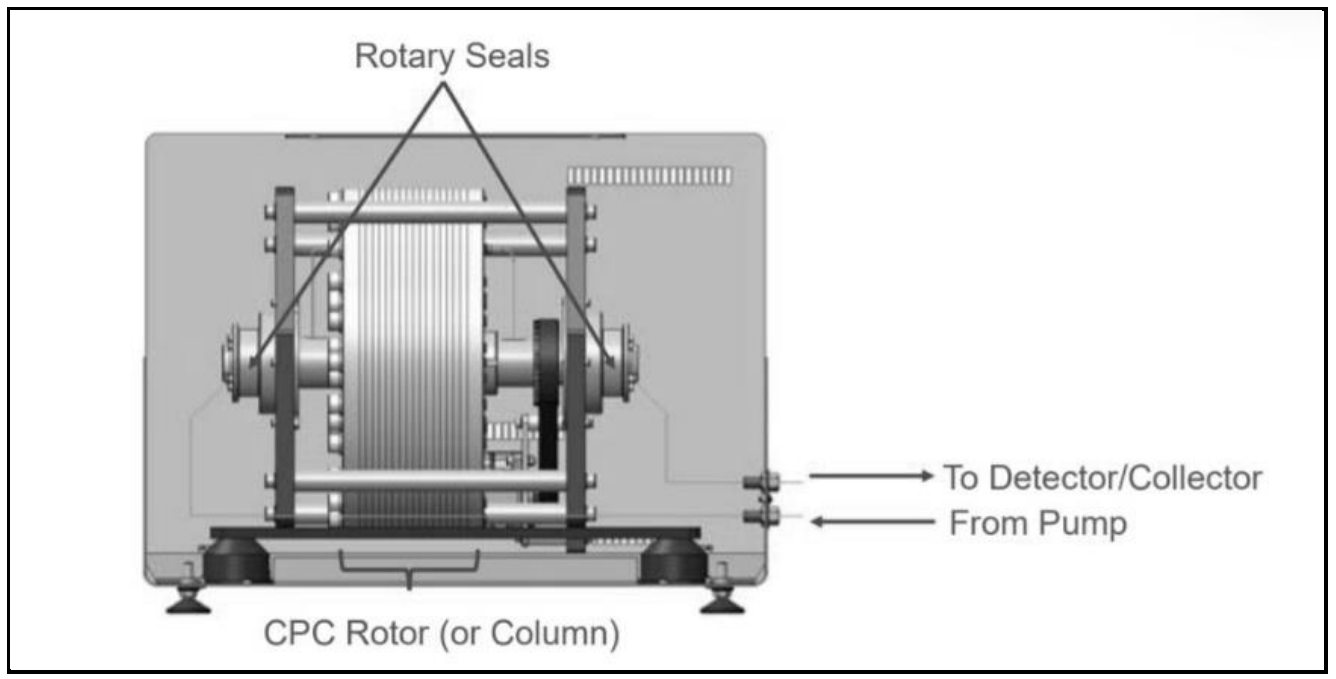

Figure 10: Representation of Centrifugal Partition Chromatography System

In terms of drawbacks, CPC technology is still relatively unknown among academics. Because it is not an analytical technique, product purity must be determined using another approach, such as analytical HPLC.

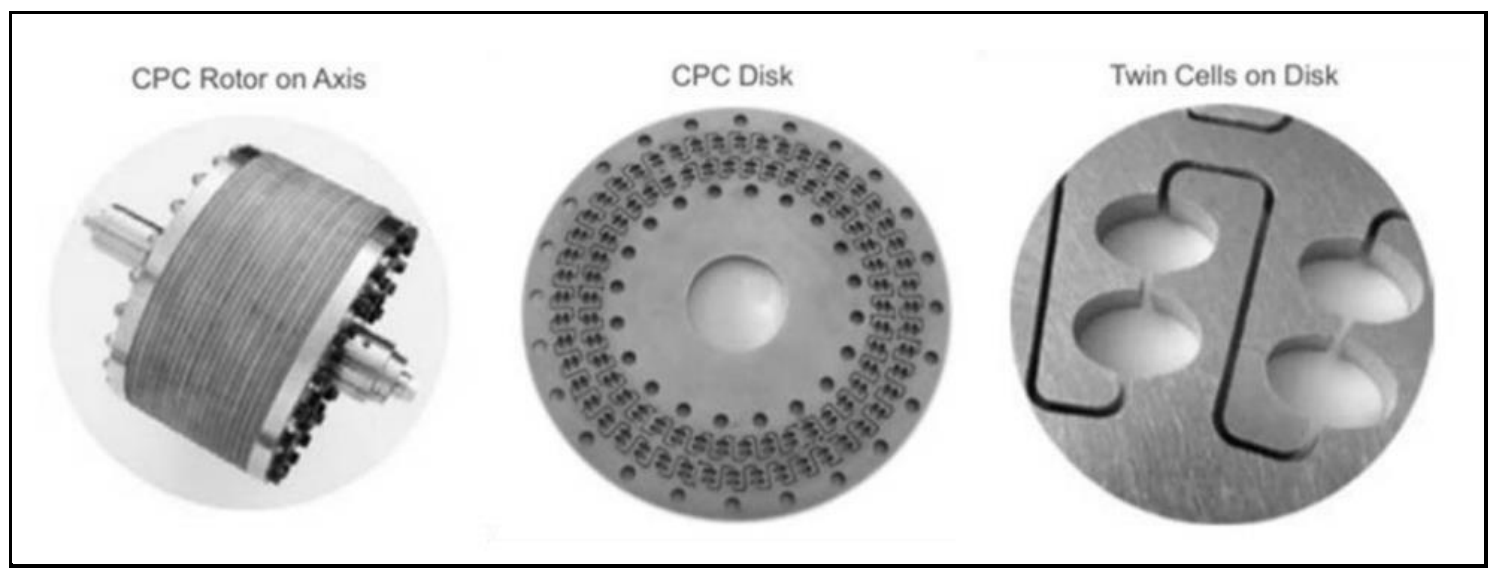

Figure 11: The discs are made up of cells linked by ducts in centrifugal partition chromatography. The discs are arranged in a column around a central axis, which is known as the CPC column. (rotor)

\section{Conclusion}

Hemp's product market capacity has increased by tenfold in less than a decade, fueled by recent prospects given by altering legislation as well as recent scientific advancements. The tested 
extraction procedures are based on those used traditionally for other biomasses, and the results achieved for hemp are, in some cases, contradictory, showing that this phase remains the bottleneck of hemp downstream processing technology.

$\mathrm{CBD}$, the most popular hemp product, presently has the most market potential and is extremely appealing for its recreational and medicinal benefits. The co-extraction of CBD's psychoactive relative, THC, provides a considerable problem during purification.

As a result, optimal extraction technology is predicted to be cannabinoid-specific as well as selective for CBD extraction. Furthermore, the chosen approach must be safe, efficient (both economically and in terms of time), and capable of optimising the yield (minimum CBD loss). Recent research has shown that supercritical fluids and organic solvents may be used to extract cannabinoids, terpenes, and fatty acids successfully.

Despite the efficacy of organic solvents in extraction, the $\mathrm{SC}-\mathrm{CO}_{2}$ appears to be preferable in terms of operational efficiency, environmental issues, and large-scale purifying technicality.

\section{References}

Abrams, Di, and M Guzman. "Cannabis in Cancer Care." Clinical Pharmacology \& Therapeutics 97, no. 6 (2015): 575-86. https://doi.org/10.1002/cpt.108.

Adesina, Ifeoluwa, Arnab Bhowmik, Harmandeep Sharma, and Abolghasem Shahbazi. "A Review on the Current State of Knowledge of Growing Conditions, Agronomic Soil Health Practices and Utilities of Hemp in the United States." Agriculture 10, no. 4 (April 2020): 129. https://doi.org/10.3390/agriculture10040129.

Agarwal, Charu, Katalin Máthé, Tamás Hofmann, and Levente Csóka. "Ultrasound-Assisted Extraction of Cannabinoids from Cannabis Sativa L. Optimized by Response Surface Methodology." Journal of Food Science 83, no. 3 (2018): 700-710. https://doi.org/10.1111/1750-3841.14075.

"Ultrasound-Assisted Extraction of Cannabinoids from Cannabis Sativa L. Optimized by Response Surface Methodology." Journal of Food Science 83, no. 3 (2018): 700-710. https://doi.org/10.1111/1750-3841.14075. 
Ahmed, Isam A. Mohamed, Fahad Y. Al-Juhaimi, Mehmet Musa Özcan, Magdi A. Osman, Mustafa A. Gassem, and Hesham A. A. Salih. "Effects of Cold-Press and Soxhlet Extraction Systems on Antioxidant Activity, Total Phenol Contents, Fatty Acids, and Tocopherol Contents of Walnut Kernel Oils." Journal of Oleo Science 68, no. 2 (2019): 167-73. https://doi.org/10.5650/jos.ess18141.

Aiello, Gilda, Elisa Fasoli, Giovanna Boschin, Carmen Lammi, Chiara Zanoni, Attilio Citterio, and Anna Arnoldi. "Proteomic Characterization of Hempseed (Cannabis Sativa L.)." Journal of Proteomics, Foodomics - Novel insights in food and nutrition domains, 147 (September 16, 2016): 187-96. https://doi.org/10.1016/j.jprot.2016.05.033.

Aizpurua-Olaizola, Oier, Izaskun Elezgarai, Irantzu Rico-Barrio, Iratxe Zarandona, Nestor Etxebarria, and Aresatz Usobiaga. "Targeting the Endocannabinoid System: Future Therapeutic Strategies.” Drug Discovery Today 22, no. 1 (January 1, 2017): 105-10. https://doi.org/10.1016/j.drudis.2016.08.005.

Aladić, Krunoslav, Kristjan Jarni, Tina Barbir, Senka Vidović, Jelena Vladić, Mate Bilić, and Stela Jokić. "Supercritical CO2 Extraction of Hemp (Cannabis Sativa L.) Seed Oil.” Industrial Crops and Products 76 (December 15, 2015): 472-78. https://doi.org/10.1016/j.indcrop.2015.07.016.

"Supercritical CO2 Extraction of Hemp (Cannabis Sativa L.) Seed Oil." Industrial Crops and Products 76 (December 15, 2015): 472-78. https://doi.org/10.1016/j.indcrop.2015.07.016.

Al-Ghezi, Zinah Zamil, Kathryn Miranda, Mitzi Nagarkatti, and Prakash S. Nagarkatti. "Combination of Cannabinoids, $\Delta 9$ - Tetrahydrocannabinol and Cannabidiol, Ameliorates Experimental Multiple Sclerosis by Suppressing Neuroinflammation Through Regulation of MiRNA-Mediated Signaling Pathways." Frontiers in Immunology 10 (2019): 1921. https://doi.org/10.3389/fimmu.2019.01921.

Appendino, Giovanni, Simon Gibbons, Anna Giana, Alberto Pagani, Gianpaolo Grassi, Michael Stavri, Eileen Smith, and M. Mukhlesur Rahman. “Antibacterial Cannabinoids from Cannabis Sativa: A Structure-Activity Study.” Journal of Natural Products 71, no. 8 (August 1, 2008): 1427-30. https://doi.org/10.1021/np8002673.

Arranz, E., L. Jaime, M. C. Lopez de la Hazas, G. Vicente, G. Reglero, and S. Santoyo. "Supercritical Sage Extracts as Anti-Inflammatory Food Ingredients." Industrial Crops and Products 54 (March 1, 2014): 159-66. https://doi.org/10.1016/j.indcrop.2014.01.021.

Atakan, Zerrin. "Cannabis, a Complex Plant: Different Compounds and Different Effects on Individuals." Therapeutic Advances in Psychopharmacology 2, no. 6 (December 1, 2012): 241-54. https://doi.org/10.1177/2045125312457586. 
Atalay, Sinemyiz, Iwona Jarocka-Karpowicz, and Elzbieta Skrzydlewska. “Antioxidative and AntiInflammatory Properties of Cannabidiol.” Antioxidants 9, no. 1 (January 2020): 21. https://doi.org/10.3390/antiox9010021.

Attard, Thomas M., Camille Bainier, Marine Reinaud, Alexandra Lanot, Simon J. McQueen-Mason, and Andrew J. Hunt. "Utilisation of Supercritical Fluids for the Effective Extraction of Waxes and Cannabidiol (CBD) from Hemp Wastes." Industrial Crops and Products 112 (February 1, 2018): 38-46. https://doi.org/10.1016/j.indcrop.2017.10.045.

Badowski, Melissa E., and Paa Kwesi Yanful. "Dronabinol Oral Solution in the Management of Anorexia and Weight Loss in AIDS and Cancer." Therapeutics and Clinical Risk Management 14 (April 6, 2018): 643-51. https://doi.org/10.2147/TCRM.S126849.

Baram, Liran, Ella Peled, Paula Berman, Ben Yellin, Elazar Besser, Maya Benami, Igal LouriaHayon, Gil M. Lewitus, and David Meiri. "The Heterogeneity and Complexity of Cannabis Extracts as Antitumor Agents." Oncotarget 10, no. 41 (June 25, 2019): 4091-4106. https://doi.org/10.18632/oncotarget.26983.

Ben-Shabat, Shimon, Ester Fride, Tzviel Sheskin, Tsippy Tamiri, Man-Hee Rhee, Zvi Vogel, Tiziana Bisogno, Luciano De Petrocellis, Vincenzo Di Marzo, and Raphael Mechoulam. “An Entourage Effect: Inactive Endogenous Fatty Acid Glycerol Esters Enhance 2-ArachidonoylGlycerol Cannabinoid Activity." European Journal of Pharmacology 353, no. 1 (July 17, 1998): 23-31. https://doi.org/10.1016/S0014-2999(98)00392-6.

Berman, Paula, Kate Futoran, Gil M. Lewitus, Dzmitry Mukha, Maya Benami, Tomer Shlomi, and David Meiri. "A New ESI-LC/MS Approach for Comprehensive Metabolic Profiling of Phytocannabinoids in Cannabis." Scientific Reports 8, no. 1 (September 24, 2018): 14280. https://doi.org/10.1038/s41598-018-32651-4.

Blasco-Benito, Sandra, Marta Seijo-Vila, Miriam Caro-Villalobos, Isabel Tundidor, Clara Andradas, Elena García-Taboada, Jeff Wade, et al. "Appraising the 'Entourage Effect': Antitumor Action of a Pure Cannabinoid versus a Botanical Drug Preparation in Preclinical Models of Breast Cancer." Biochemical Pharmacology, Cannabinoid Pharmacology and Therapeutics in Spain, 157 (November 1, 2018): 285-93. https://doi.org/10.1016/j.bcp.2018.06.025.

Brenneisen, Rudolf. "Chemistry and Analysis of Phytocannabinoids and Other Cannabis Constituents." In Marijuana and the Cannabinoids, edited by Mahmoud A. ElSohly, 17-49. Forensic Science And Medicine. Totowa, NJ: Humana Press, 2007. https://doi.org/10.1007/978-1-59259-947-9_2. 
Brighenti, Virginia, Federica Pellati, Marleen Steinbach, Davide Maran, and Stefania Benvenuti. "Development of a New Extraction Technique and HPLC Method for the Analysis of NonPsychoactive Cannabinoids in Fibre-Type Cannabis Sativa L. (Hemp)." Journal of Pharmaceutical and Biomedical Analysis 143 (September 5, 2017): 228-36. https://doi.org/10.1016/j.jpba.2017.05.049.

Chandra, Suman, Mahmoud A. ElSohly, and Hemant Lata, eds. Cannabis Sativa L. - Botany and Biotechnology. 1st ed. 2017. Cham: Springer International Publishing: Imprint: Springer, 2017. https://doi.org/10.1007/978-3-319-54564-6.

Chang, Chih-Wei, Ching-Chi Yen, Ming-Tsang Wu, Mei-Chich Hsu, and Yu-Tse Wu. "MicrowaveAssisted Extraction of Cannabinoids in Hemp Nut Using Response Surface Methodology: Optimization and Comparative Study." Molecules 22, no. 11 (November 2017): 1894. https://doi.org/10.3390/molecules22111894.

Chawankul, Nongluk, Supaporn Chuaprasert, Peter Douglas, and Wilai Luewisutthichat. "Simulation of an Agitated Thin Film Evaporator for Concentrating Orange Juice Using AspenPlusTM." Journal of Food Engineering 47, no. 4 (March 1, 2001): 247-53. https://doi.org/10.1016/S0260-8774(00)00122-9.

Chemat, Farid, Maryline Abert Vian, Anne-Sylvie Fabiano-Tixier, Marinela Nutrizio, Anet Režek Jambrak, Paulo E. S. Munekata, Jose M. Lorenzo, Francisco J. Barba, Arianna Binello, and Giancarlo Cravotto. “A Review of Sustainable and Intensified Techniques for Extraction of Food and Natural Products." Green Chemistry 22, no. 8 (April 27, 2020): 2325-53. https://doi.org/10.1039/C9GC03878G.

Chen, Jeffrey W., Laura M. Borgelt, and Allison B. Blackmer. "Cannabidiol: A New Hope for Patients With Dravet or Lennox-Gastaut Syndromes." Annals of Pharmacotherapy 53, no. 6 (June 1, 2019): 603-11. https://doi.org/10.1177/1060028018822124.

Christinat, Nicolas, Marie-Claude Savoy, and Pascal Mottier. "Development, Validation and Application of a LC-MS/MS Method for Quantification of 15 Cannabinoids in Food." Food Chemistry 318 (July 15, 2020): 126469. https://doi.org/10.1016/j.foodchem.2020.126469.

Crescente, Giuseppina, Simona Piccolella, Assunta Esposito, Monica Scognamiglio, Antonio Fiorentino, and Severina Pacifico. "Chemical Composition and Nutraceutical Properties of Hempseed: An Ancient Food with Actual Functional Value.” Phytochemistry Reviews 17, no. 4 (August 1, 2018): 733-49. https://doi.org/10.1007/s11101-018-9556-2.

Da Porto, C., D. Decorti, and F. Tubaro. "Fatty Acid Composition and Oxidation Stability of Hemp (Cannabis Sativa L.) Seed Oil Extracted by Supercritical Carbon Dioxide." Industrial Crops and Products 36, no. 1 (March 1, 2012): 401-4. https://doi.org/10.1016/j.indcrop.2011.09.015. 
Da Porto, C., D. Voinovich, D. Decorti, and A. Natolino. "Response Surface Optimization of Hemp Seed (Cannabis Sativa L.) Oil Yield and Oxidation Stability by Supercritical Carbon Dioxide Extraction." The Journal of Supercritical Fluids 68 (August 1, 2012): 45-51. https://doi.org/10.1016/j.supflu.2012.04.008.

Da Porto, Carla, Deborha Decorti, and Andrea Natolino. "Separation of Aroma Compounds from Industrial Hemp Inflorescences (Cannabis Sativa L.) by Supercritical CO2 Extraction and onLine Fractionation." Industrial Crops and Products 58 (July 1, 2014): 99-103. https://doi.org/10.1016/j.indcrop.2014.03.042.

Dariš, Barbara, Mojca Tancer Verboten, Željko Knez, and Polonca Ferk. "Cannabinoids in Cancer Treatment: Therapeutic Potential and Legislation.” Bosnian Journal of Basic Medical Sciences 19, no. 1 (February 12, 2019): 14-23. https://doi.org/10.17305/bjbms.2018.3532.

De Vita, Daniela, Valentina Noemi Madia, Valeria Tudino, Francesco Saccoliti, Alessandro De Leo, Antonella Messore, Patrizia Roscilli, et al. "Comparison of Different Methods for the Extraction of Cannabinoids from Cannabis." Natural Product Research 34, no. 20 (October 17, 2020): 2952-58. https://doi.org/10.1080/14786419.2019.1601194.

Devi, Vibha, and Shabina Khanam. "Comparative Study of Different Extraction Processes for Hemp (Cannabis Sativa) Seed Oil Considering Physical, Chemical and Industrial-Scale Economic Aspects." Journal of Cleaner Production 207 (January 10, 2019): 645-57. https://doi.org/10.1016/j.jclepro.2018.10.036.

Di Marzo, Vincenzo. "New Approaches and Challenges to Targeting the Endocannabinoid System." Nature Reviews Drug Discovery 17, no. 9 (September 2018): 623-39. https://doi.org/10.1038/nrd.2018.115.

Djeridane, A., M. Yousfi, B. Nadjemi, D. Boutassouna, P. Stocker, and N. Vidal. "Antioxidant Activity of Some Algerian Medicinal Plants Extracts Containing Phenolic Compounds." Food Chemistry 97, no. 4 (August 1, 2006): 654-60. https://doi.org/10.1016/j.foodchem.2005.04.028.

Drinić, Zorica, Jelena Vladić, Anamarija Koren, Tijana Zeremski, Nadežda Stojanov, Biljana Kiprovski, and Senka Vidović. "Microwave-Assisted Extraction of Cannabinoids and Antioxidants from Cannabis Sativa Aerial Parts and Process Modeling." Journal of Chemical Technology \& Biotechnology 95, no. 3 (2020): 831-39. https://doi.org/10.1002/jctb.6273.

Dutta, Ratna, Ujjaini Sarkar, and Alakananda Mukherjee. "Extraction of Oil from Crotalaria Juncea Seeds in a Modified Soxhlet Apparatus: Physical and Chemical Characterization of a Prospective Bio-Fuel.” Fuel 116 (January 15, 2014): 794-802. https://doi.org/10.1016/j.fuel.2013.08.056. 
Dzierżanowski, Tomasz. "Prospects for the Use of Cannabinoids in Oncology and Palliative Care Practice: A Review of the Evidence." Cancers 11, no. 2 (February 2019): 129. https://doi.org/10.3390/cancers11020129.

Eggers, R. "Extraktion von Fettrohstoffen mit überkritischem CO2." Lipid / Fett 96, no. S2 (1994): 513-18. https://doi.org/10.1002/lipi.19940961401.

Ekezie, Flora-Glad Chizoba, Da-Wen Sun, and Jun-Hu Cheng. "Acceleration of MicrowaveAssisted Extraction Processes of Food Components by Integrating Technologies and Applying Emerging Solvents: A Review of Latest Developments.” Trends in Food Science \& Technology 67 (September 1, 2017): 160-72. https://doi.org/10.1016/j.tifs.2017.06.006.

ElSohly, Mahmoud A., and Desmond Slade. "Chemical Constituents of Marijuana: The Complex Mixture of Natural Cannabinoids." Life Sciences, NATURECEUTICALS (NATURAL PRODUCTS), NUTRACEUTICALS, HERBAL BOTANICALS, AND PSYCHOACTIVES: DRUG DISCOVERY AND DRUG-DRUG INTERACTIONS, 78, no. 5 (December 22, 2005): 539-48. https://doi.org/10.1016/j.lfs.2005.09.011.

Federica, Pollastro, Minassi Alberto, and Grazia Fresu Luigia. "Cannabis Phenolics and Their Bioactivities.” Current Medicinal Chemistry 25, no. 10 (February 28, 2018): 1160-85.

Fine, Perry G., and Mark J. Rosenfeld. "Cannabinoids for Neuropathic Pain." Current Pain and Headache Reports 18, no. 10 (August 28, 2014): 451. https://doi.org/10.1007/s11916-014$\underline{0451-2 .}$

Fiorini, Dennis, Arnaud Molle, Massimo Nabissi, Giuseppe Santini, Giovanni Benelli, and Filippo Maggi. "Valorizing Industrial Hemp (Cannabis Sativa L.) by-Products: Cannabidiol Enrichment in the Inflorescence Essential Oil Optimizing Sample Pre-Treatment Prior to Distillation." Industrial Crops and Products 128 (February 1, 2019): 581-89. https://doi.org/10.1016/j.indcrop.2018.10.045.

Franklin, Ross M., Ed Rosenthal, and Rachel Melissa Franklin. Method for conducing concentrated cannabis oil to be stable, emulsifiable and flavorless for use in hot beverages and resulting powderized cannabis oil. United States US9629886B2, filed February 22, 2016, and issued April 25, 2017. https://patents.google.com/patent/US9629886B2/en.

Galanakis, Charis M. "Recovery of High Added-Value Components from Food Wastes: Conventional, Emerging Technologies and Commercialized Applications." Trends in Food Science \& Technology 26, no. 2 (August 1, 2012): 68-87. https://doi.org/10.1016/j.tifs.2012.03.003.

Gallego, Rocío, Mónica Bueno, and Miguel Herrero. "Sub- and Supercritical Fluid Extraction of Bioactive Compounds from Plants, Food-by-Products, Seaweeds and Microalgae - An 
Update." TrAC Trends in Analytical Chemistry 116 (July 1, 2019): 198-213. https://doi.org/10.1016/j.trac.2019.04.030.

Melo, M. M. R. de, A. J. D. Silvestre, and C. M. Silva. "Supercritical Fluid Extraction of Vegetable Matrices: Applications, Trends and Future Perspectives of a Convincing Green Technology." The Journal of Supercritical Fluids 92 (August 1, 2014): 115-76. https://doi.org/10.1016/j.supflu.2014.04.007.

Gallo-Molina, Ada C., Henry I. Castro-Vargas, William F. Garzón-Méndez, Jorge A. Martínez Ramírez, Zully J. Rivera Monroy, Jerry W. King, and Fabian Parada-Alfonso. "Extraction, Isolation and Purification of Tetrahydrocannabinol from the Cannabis Sativa L. Plant Using Supercritical Fluid Extraction and Solid Phase Extraction.” The Journal of Supercritical Fluids 146 (April 1, 2019): 208-16. https://doi.org/10.1016/j.supflu.2019.01.020.

Garrett, Edward R., and C. Anthony Hunt. "Physicochemical Properties, Solubility, and Protein Binding of $\Delta 9$-Tetrahydrocannabinol.” Journal of Pharmaceutical Sciences 63, no. 7 (July 1, 1974): 1056-64. https://doi.org/10.1002/jps.2600630705.

Glivar, Taja, Jan Eržen, Samo Kreft, Marjeta Zagožen, Andreja Čerenak, Barbara Čeh, and Eva Tavčar Benković. "Cannabinoid Content in Industrial Hemp (Cannabis Sativa L.) Varieties Grown in Slovenia." Industrial Crops and Products 145 (March 1, 2020): 112082. https://doi.org/10.1016/j.indcrop.2019.112082.

Gradisnik, Lidija, Martin Trapecar, Marjan Slak Rupnik, and Tomaz Velnar. "HUIEC, Human Intestinal Epithelial Cell Line with Differentiated Properties: Process of Isolation and Characterisation." Wiener Klinische Wochenschrift 127, no. 5 (December 1, 2015): 204-9. https://doi.org/10.1007/s00508-015-0771-1.

Grijó, Daniel Ribeiro, Ignacio Alberto Vieitez Osorio, and Lúcio Cardozo-Filho. "Supercritical Extraction Strategies Using CO2 and Ethanol to Obtain Cannabinoid Compounds from Cannabis Hybrid Flowers." Journal of CO2 Utilization 28 (December 1, 2018): 174-80. https://doi.org/10.1016/j.jcou.2018.09.022.

Gülck, Thies, and Birger Lindberg Møller. "Phytocannabinoids: Origins and Biosynthesis." Trends in Plant Science 25, no. 10 (October 1, 2020): 985-1004. https://doi.org/10.1016/j.tplants.2020.05.005.

Hadolin, Majda, Mojca S̆kerget, Željko Knez, and Davorin Bauman. "High Pressure Extraction of Vitamin E-Rich Oil from Silybum Marianum.” Food Chemistry 74, no. 3 (August 1, 2001): 355-64. https://doi.org/10.1016/S0308-8146(01)00152-2. 
Halim, Ronald, Michael K. Danquah, and Paul A. Webley. "Extraction of Oil from Microalgae for Biodiesel Production: A Review.” Biotechnology Advances 30, no. 3 (May 1, 2012): 709-32. https://doi.org/10.1016/j.biotechadv.2012.01.001.

Hanuš, Lumír Ondřej, Stefan Martin Meyer, Eduardo Muñoz, Orazio Taglialatela-Scafati, and Giovanni Appendino. "Phytocannabinoids: A Unified Critical Inventory." Natural Product Reports 33, no. 12 (November 23, 2016): 1357-92. https://doi.org/10.1039/C6NP00074F.

Herrero, Miguel, Alejandro Cifuentes, and Elena Ibañez. "Sub- and Supercritical Fluid Extraction of Functional Ingredients from Different Natural Sources: Plants, Food-by-Products, Algae and Microalgae: A Review." Food Chemistry 98, no. 1 (January 1, 2006): 136-48. https://doi.org/10.1016/j.foodchem.2005.05.058.

Hinz, Burkhard, and Robert Ramer. "Anti-Tumour Actions of Cannabinoids.” British Journal of Pharmacology 176, no. 10 (2019): 1384-94. https://doi.org/10.1111/bph.14426.

Hong, Glenn T. "Supercritical Fluid Extraction By Larry T. Taylor (Virginia Polytechnic Institute and State University). John Wiley \& Sons, New York, NY. 1996. Xvi + 181 Pp. $15 \times 22.5$ Cm. \$49.95. ISBN 0-471-11990-3.” Journal of Natural Products 59, no. 12 (January 1, 1996): 1215-1215. https://doi.org/10.1021/np960462j.

House, James D., Jason Neufeld, and Gero Leson. "Evaluating the Quality of Protein from Hemp Seed (Cannabis Sativa L.) Products Through the Use of the Protein Digestibility-Corrected Amino Acid Score Method." Journal of Agricultural and Food Chemistry 58, no. 22 (November 24, 2010): 11801-7. https://doi.org/10.1021/jf102636b.

Izzo, Angelo A, Raffaele Capasso, Gabriella Aviello, Francesca Borrelli, Barbara Romano, Fabiana Piscitelli, Laura Gallo, Francesco Capasso, Pierangelo Orlando, and Vincenzo Di Marzo. "Inhibitory Effect of Cannabichromene, a Major Non-Psychotropic Cannabinoid Extracted from Cannabis Sativa, on Inflammation-Induced Hypermotility in Mice.” British Journal of Pharmacology 166, no. 4 (2012): 1444-60. https://doi.org/10.1111/j.1476-5381.2012.01879.x. Jadhav, Dnyaneshwar, Rekha B.n., Parag R. Gogate, and Virendra K. Rathod. "Extraction of Vanillin from Vanilla Pods: A Comparison Study of Conventional Soxhlet and Ultrasound Assisted Extraction.” Journal of Food Engineering 93, no. 4 (August 1, 2009): 421-26. https://doi.org/10.1016/j.jfoodeng.2009.02.007.

Jingbang, Liang. "Value-Addition of Cold Pressed Hemp Seed Oil and Oil by-Products through Ultrasonic Bleaching and Heat Treatment: Evaluation of Chlorophyll, Oxidative Stability and $\begin{array}{llll}\text { Antioxidant } & \text { Activity, } & \text { September } & 29,\end{array}$ https://mspace.lib.umanitoba.ca/xmlui/handle/1993/32207. 
Karamé, Iyad, Janah Shaya, and Hassan Srour. Carbon Dioxide Chemistry, Capture and Oil Recovery. BoD - Books on Demand, 2018.

Katalinic, V., M. Milos, T. Kulisic, and M. Jukic. "Screening of 70 Medicinal Plant Extracts for Antioxidant Capacity and Total Phenols.” Food Chemistry 94, no. 4 (March 1, 2006): 550-57. https://doi.org/10.1016/j.foodchem.2004.12.004.

Kedare, Sagar B., and R. P. Singh. "Genesis and Development of DPPH Method of Antioxidant Assay." Journal of Food Science and Technology 48, no. 4 (August 1, 2011): 412-22. https://doi.org/10.1007/s13197-011-0251-1.

Kianimanesh, Hamid Reza, Farzin Abbaspour-Aghdam, and Mehrab Valizadeh Derakhshan. "Biodiesel Production from Vegetable Oil: Process Design, Evaluation and Optimization." Polish Journal of Chemical Technology 19, no. 3 (September 1, 2017): 49-55. https://doi.org/10.1515/pjct-2017-0048.

King, Jerry W. "The Relationship between Cannabis/Hemp Use in Foods and Processing Methodology." Current Opinion in Food Science, Cannabis Oil Extraction, Purification, Utilization - Innovations in Food Science * Omics approaches for food analysis \& authentication, 28 (August 1, 2019): 32-40. https://doi.org/10.1016/j.cofs.2019.04.007.

"The Relationship between Cannabis/Hemp Use in Foods and Processing Methodology." Current Opinion in Food Science, Cannabis Oil Extraction, Purification, Utilization - Innovations in Food Science * Omics approaches for food analysis \& authentication, 28 (August 1, 2019): 32-40. https://doi.org/10.1016/j.cofs.2019.04.007.

Kitrytė, Vaida, Dovyda Bagdonaite, and Petras Rimantas Venskutonis. "Biorefining of Industrial Hemp (Cannabis Sativa L.) Threshing Residues into Cannabinoid and Antioxidant Fractions by Supercritical Carbon Dioxide, Pressurized Liquid and Enzyme-Assisted Extractions." Food Chemistry, 1st Food Chemistry Conference: Shaping the future of food quality, health and safety, 267 (November 30, 2018): 420-29. https://doi.org/10.1016/j.foodchem.2017.09.080.

Ko, Ryan Delmoral, Brock Hughes, Krupal Pal, and Alexzander Samuelsson. Cannabinoid extraction process using brine. United States US10406453B2, filed August 24, 2018, and issued September 10, 2019. https://patents.google.com/patent/US10406453B2/en.

Kostić, Milan D., Nataša M. Joković, Olivera S. Stamenković, Katarina M. Rajković, Petar S. Milić, and Vlada B. Veljković. "The Kinetics and Thermodynamics of Hempseed Oil Extraction by N-Hexane." Industrial Crops and Products 52 (January 1, 2014): 679-86. https://doi.org/10.1016/j.indcrop.2013.11.045.

Köszegi, Kornélia, Gyula Vatai, and Erika Békássy-Molnár. "Comparison the Soxhlet and Supercritical Fluid Extraction of Nettle Root (Urtica Dioica L.).” Periodica Polytechnica 
Chemical Engineering 59, no. 3 (February 18, 2015): 168-73. https://doi.org/10.3311/PPch.7582.

Koturbash, Igor, and Douglas MacKay. "Cannabidiol and Other Cannabinoids: From Toxicology and Pharmacology to the Development of a Regulatory Pathway." Journal of Dietary $\begin{array}{llllll}\text { Supplements } & 17, \quad \text { no. } & 5 & \text { (September } & 2, & 2020 \text { ): 487-92. }\end{array}$ https://doi.org/10.1080/19390211.2020.1796886.

Kraujalis, Paulius, Vaida Kraujalienè, Rita Kazernavičiūtè, and Petras Rimantas Venskutonis. "Supercritical Carbon Dioxide and Pressurized Liquid Extraction of Valuable Ingredients from Viburnum Opulus Pomace and Berries and Evaluation of Product Characteristics." The Journal of Supercritical Fluids $122 \quad$ (April 1, 2017): 99-108. https://doi.org/10.1016/j.supflu.2016.12.008.

Kriese, U., E. Schumann, W.E. Weber, M. Beyer, L. Brühl, and Matthäus. “Oil Content, Tocopherol Composition and Fatty Acid Patterns of the Seeds of 51 Cannabis Sativa L. Genotypes." $\begin{array}{llllll}\text { Euphytica } & 137, & \text { no. } & 3 & \text { (June } & 1,\end{array}$ https://doi.org/10.1023/B:EUPH.0000040473.23941.76.

Křížek, Tomáš, Miroslava Bursová, Rachel Horsley, Martin Kuchař, Petr Tůma, Radomír Čabala, and Tomáš Hložek. "Menthol-Based Hydrophobic Deep Eutectic Solvents: Towards Greener and Efficient Extraction of Phytocannabinoids." Journal of Cleaner Production 193 (August 20, 2018): 391-96. https://doi.org/10.1016/j.jclepro.2018.05.080.

Lang, Qingyong, and Chien M. Wai. "Supercritical Fluid Extraction in Herbal and Natural Product Studies - a Practical Review." Talanta 53, no. 4 (January 5, 2001): 771-82. https://doi.org/10.1016/S0039-9140(00)00557-9.

Leiman, Kristiina, Lorenzo Colomo, Sergio Armenta, Miguel de la Guardia, and Francesc A. Esteve-Turrillas. "Fast Extraction of Cannabinoids in Marijuana Samples by Using Hard-Cap Espresso Machines.” Talanta 190 (December 1, 2018): 321-26. https://doi.org/10.1016/j.talanta.2018.08.009.

Lewis-Bakker, Melissa M., Yi Yang, Rupali Vyawahare, and Lakshmi P. Kotra. "Extractions of Medical Cannabis Cultivars and the Role of Decarboxylation in Optimal Receptor Responses." Cannabis and Cannabinoid Research 4, no. 3 (September 1, 2019): 183-94. https://doi.org/10.1089/can.2018.0067.

Lingyan, Ye, Cao Zheng, Wang Weiwei, and Zhou Naiming. "New Insights in Cannabinoid Receptor Structure and Signaling." Current Molecular Pharmacology 12, no. 3 (July 31, 2019): $239-48$.

Linnaeus, Charles. Species plantarum. Impensis G. C. Nauk, 1799. 
Lukhele, Sindiswa T., and Lesetja R. Motadi. "Cannabidiol Rather than Cannabis Sativa Extracts Inhibit Cell Growth and Induce Apoptosis in Cervical Cancer Cells.” BMC Complementary and Alternative Medicine 16, no. 1 (September 1, 2016): 335. https://doi.org/10.1186/s12906016-1280-0.

Mamun, Md Abdullah Al. "Safe Storage Guidelines for Industrial Hemp (Cannabis Sativa) Seeds," 2018- , 2018-08-24 2018. https://mspace.lib.umanitoba.ca/xmlui/handle/1993/33358.

Marchini, Marie, Céline Charvoz, Laurence Dujourdy, Nicolas Baldovini, and Jean-Jacques Filippi. "Multidimensional Analysis of Cannabis Volatile Constituents: Identification of 5,5-Dimethyl1-Vinylbicyclo[2.1.1]Hexane as a Volatile Marker of Hashish, the Resin of Cannabis Sativa L.” Journal of Chromatography A 1370 (November 28, 2014): 200-215. https://doi.org/10.1016/j.chroma.2014.10.045.

Marcu, Jahan P. "Chapter 62 - An Overview of Major and Minor Phytocannabinoids." In Neuropathology of Drug Addictions and Substance Misuse, edited by Victor R. Preedy, 67278. San Diego: Academic Press, 2016. https://doi.org/10.1016/B978-0-12-800213-1.00062-6. Mark, Tyler, Jonathan Shepherd, David Olson, William Snell, Susan Proper, and Suzanne Thornsbury, eds. Economic Viability of Industrial Hemp in the United States: A Review of State Pilot Programs. Economic Information Bulletin Number 217, 2020. https://doi.org/10.22004/ag.econ.302486.

Marques, Gisela, José C. del Río, and Ana Gutiérrez. "Lipophilic Extractives from Several Nonwoody Lignocellulosic Crops (Flax, Hemp, Sisal, Abaca) and Their Fate during Alkaline Pulping and TCF/ECF Bleaching." Bioresource Technology 101, no. 1 (January 1, 2010): 26067. https://doi.org/10.1016/j.biortech.2009.08.036.

Massi, P., A. Vaccani, S. Bianchessi, B. Costa, P. Macchi, and D. Parolaro. "The Non-Psychoactive Cannabidiol Triggers Caspase Activation and Oxidative Stress in Human Glioma Cells." Cellular and Molecular Life Sciences CMLS 63, no. 17 (September 1, 2006): 2057-66. https://doi.org/10.1007/s00018-006-6156-X.

Matthäus, Bertrand, and Ludger Brühl. "Virgin Hemp Seed Oil: An Interesting Niche Product." European Journal of Lipid Science and Technology 110, no. 7 (2008): 655-61. https://doi.org/10.1002/ejlt.200700311.

McPartland, John M., and Ethan B. Russo. "Cannabis and Cannabis Extracts.” Journal of Cannabis Therapeutics 1, no. 3-4 (June 1, 2001): 103-32. https://doi.org/10.1300/J175v01n03 08.

Mechoulam, Raphael, and Linda A. Parker. "The Endocannabinoid System and the Brain.” Annual Review of Psychology 64, no. 1 (January 3, 2013): 21-47. https://doi.org/10.1146/annurevpsych-113011-143739. 
Medina-Torres, Nelly, Teresa Ayora-Talavera, Hugo Espinosa-Andrews, Angeles SánchezContreras, and Neith Pacheco. "Ultrasound Assisted Extraction for the Recovery of Phenolic Compounds from Vegetable Sources." Agronomy 7, no. 3 (September 2017): 47. https://doi.org/10.3390/agronomy7030047.

Moreno, Teresa, Fernando Montanes, Stephen J. Tallon, Tina Fenton, and Jerry W. King. "Extraction of Cannabinoids from Hemp (Cannabis Sativa L.) Using High Pressure Solvents: An Overview of Different Processing Options." The Journal of Supercritical Fluids 161 (July 1, 2020): 104850. https://doi.org/10.1016/j.supflu.2020.104850.

Moslavac, Tihomir, Stela Jokić, Drago Šubarić, Krunoslav Aladić, Josipa Vukoja, and Nikolina Prce. "Pressing and Supercritical CO2 Extraction of Camelina Sativa Oil." Industrial Crops and Products 54 (March 1, 2014): 122-29. https://doi.org/10.1016/j.indcrop.2014.01.019.

Mourtzinos, Ioannis, Nikolaos Menexis, Dimitrios Iakovidis, Dimitris P. Makris, and Athanasia Goula. "A Green Extraction Process to Recover Polyphenols from Byproducts of Hemp Oil Processing." Recycling 3, no. 2 (June 2018): 15. https://doi.org/10.3390/recycling3020015.

Mueller, Adam. Method for producing an extract from cannabis plant matter, containing a tetrahydrocannabinol and a cannabidiol and cannabis extracts. United States US8895078B2, filed October 16, 2001, and issued November 25, 2014. https://patents.google.com/patent/US8895078B2/en.

Muñiz-Márquez, Diana B., Guillermo C. Martínez-Ávila, Jorge E. Wong-Paz, Ruth BelmaresCerda, Raúl Rodríguez-Herrera, and Cristóbal N. Aguilar. "Ultrasound-Assisted Extraction of Phenolic Compounds from Laurus Nobilis L. and Their Antioxidant Activity." Ultrasonics Sonochemistry 20, no. 5 (September 1, 2013): 1149-54. https://doi.org/10.1016/j.ultsonch.2013.02.008.

Nakahara, Yuji, and Hitoshi Sekine. "Studies on Confirmation of Cannabis Use. I. Determination of the Cannabinoid Contents in Marijuana Cigarette, Tar, and Ash Using High Performance Liquid Chromatography with Electrochemical Detection*." Journal of Analytical Toxicology 9, no. 3 (May 1, 1985): 121-24. https://doi.org/10.1093/jat/9.3.121.

Nallathambi, Rameshprabu, Moran Mazuz, Dvory Namdar, Michal Shik, Diana Namintzer, Ajjampura C. Vinayaka, Aurel Ion, et al. "Identification of Synergistic Interaction Between Cannabis-Derived Compounds for Cytotoxic Activity in Colorectal Cancer Cell Lines and Colon Polyps That Induces Apoptosis-Related Cell Death and Distinct Gene Expression." Cannabis and Cannabinoid Research 3, no. 1 (December 1, 2018): 120-35. https://doi.org/10.1089/can.2018.0010. 
Namdar, Dvory, Moran Mazuz, Aurel Ion, and Hinanit Koltai. "Variation in the Compositions of Cannabinoid and Terpenoids in Cannabis Sativa Derived from Inflorescence Position along the Stem and Extraction Methods.” Industrial Crops and Products 113 (March 1, 2018): 376-82. https://doi.org/10.1016/j.indcrop.2018.01.060.

Nuapia, Yannick, Hlanganani Tutu, Luke Chimuka, and Ewa Cukrowska. "Selective Extraction of Cannabinoid Compounds from Cannabis Seed Using Pressurized Hot Water Extraction.” Molecules 25, no. 6 (January 2020): 1335. https://doi.org/10.3390/molecules25061335.

"Selective Extraction of Cannabinoid Compounds from Cannabis Seed Using Pressurized Hot Water Extraction." Molecules 25, no. 6 (January 2020): 1335. https://doi.org/10.3390/molecules25061335.

Oseyko, Mykola, Nataliia Sova, Maryna Lutsenko, and Viktoriia Kalyna. "Chemical Aspects of the Composition of Industrial Hemp Seed Products." Ukrainian Food Journal 8, no. 3 (September 2019): 544-59. https://doi.org/10.24263/2304-974X-2019-8-3-11.

Pandohee, Jessica, Brendan J. Holland, Bingshan Li, Takuya Tsuzuki, Paul G. Stevenson, Neil W. Barnett, James R. Pearson, Oliver A.H. Jones, and Xavier A. Conlan. "Screening of Cannabinoids in Industrial-Grade Hemp Using Two-Dimensional Liquid Chromatography Coupled with Acidic Potassium Permanganate Chemiluminescence Detection." Journal of Separation Science 38, no. 12 (2015): 2024-32. https://doi.org/10.1002/jssc.201500088.

Pegoraro, Cesar N., Diego Nutter, Mario Thevenon, and Cristina L. Ramirez. "Chemical Profiles of Cannabis Sativa Medicinal Oil Using Different Extraction and Concentration Methods." Natural Product Research 35, no. 13 (July 3, 2021): 2249-52. https://doi.org/10.1080/14786419.2019.1663515.

Pellati, Federica, Virginia Brighenti, Johanna Sperlea, Lucia Marchetti, Davide Bertelli, and Stefania Benvenuti. "New Methods for the Comprehensive Analysis of Bioactive Compounds in Cannabis Sativa L. (Hemp).” Molecules 23, no. 10 (October 2018): 2639. https://doi.org/10.3390/molecules23102639.

Perrotin-Brunel, Helene, Wim Buijs, Jaap van Spronsen, Maaike J. E. van Roosmalen, Cor J. Peters, Rob Verpoorte, and Geert-Jan Witkamp. "Decarboxylation of $\Delta 9$-Tetrahydrocannabinol: Kinetics and Molecular Modeling." Journal of Molecular Structure 987, no. 1 (February 22, 2011): 67-73. https://doi.org/10.1016/j.molstruc.2010.11.061.

Perrotin-Brunel, Helene, Maaike C. Kroon, Maaike J. E. van Roosmalen, Jaap van Spronsen, Cor J. Peters, and Geert-Jan Witkamp. "Solubility of Non-Psychoactive Cannabinoids in Supercritical Carbon Dioxide and Comparison with Psychoactive Cannabinoids.” The Journal 
of Supercritical Fluids, 100th year Anniversary of van der Waals' Nobel Lecture, 55, no. 2 (December 1, 2010): 603-8. https://doi.org/10.1016/j.supflu.2010.09.011.

"Solubility of Non-Psychoactive Cannabinoids in Supercritical Carbon Dioxide and Comparison with Psychoactive Cannabinoids." The Journal of Supercritical Fluids, 100th year Anniversary of van der Waals' Nobel Lecture, 55, no. 2 (December 1, 2010): 603-8. https://doi.org/10.1016/j.supflu.2010.09.011.

"Solubility of Non-Psychoactive Cannabinoids in Supercritical Carbon Dioxide and Comparison with Psychoactive Cannabinoids.” The Journal of Supercritical Fluids, 100th year Anniversary of van der Waals' Nobel Lecture, 55, no. 2 (December 1, 2010): 603-8. https://doi.org/10.1016/j.supflu.2010.09.011.

Perrotin-Brunel, Helene, Pablo Cabeza Perez, Maaike J. E. van Roosmalen, Jaap van Spronsen, Geert-Jan Witkamp, and Cor J. Peters. "Solubility of $\Delta$ 9-Tetrahydrocannabinol in Supercritical Carbon Dioxide: Experiments and Modeling.” The Journal of Supercritical Fluids 52, no. 1 (February 1, 2010): 6-10. https://doi.org/10.1016/j.supflu.2009.12.001.

Pertwee, R G. "The Diverse CB1 and CB2 Receptor Pharmacology of Three Plant Cannabinoids: $\Delta$ 9-Tetrahydrocannabinol, Cannabidiol and $\Delta 9$-Tetrahydrocannabivarin." British Journal of Pharmacology 153, no. 2 (2008): 199-215. https://doi.org/10.1038/sj.bjp.0707442.

Peters, Hélène, and Gabriel G. Nahas. "A Brief History of Four Millennia (B.C. 2000-A.D. 1974)." In Marihuana and Medicine, edited by Gabriel G. Nahas, Kenneth M. Sutin, David Harvey, Stig Agurell, Nicholas Pace, and Robert Cancro, 3-7. Totowa, NJ: Humana Press, 1999. https://doi.org/10.1007/978-1-59259-710-9 1.

Plaza, Merichel, and Charlotta Turner. "Pressurized Hot Water Extraction of Bioactives." TrAC Trends in Analytical Chemistry, Green Extraction Techniques, 71 (September 1, 2015): 39-54. https://doi.org/10.1016/j.trac.2015.02.022.

Pojić, Milica, Aleksandra Mišan, Marijana Sakač, Tamara Dapčević Hadnađev, Bojana Šarić, Ivan Milovanović, and Miroslav Hadnađev. "Characterization of Byproducts Originating from Hemp Oil Processing." Journal of Agricultural and Food Chemistry 62, no. 51 (December 24, 2014): 12436-42. https://doi.org/10.1021/jf5044426.

Pollio, Antonino. "The Name of Cannabis: A Short Guide for Nonbotanists." Cannabis and Cannabinoid Research 1, no. 1 (December 1, 2016): 234-38. https://doi.org/10.1089/can.2016.0027.

Rahn, Elizabeth J., and Andrea G. Hohmann. "Cannabinoids as Pharmacotherapies for Neuropathic Pain: From the Bench to the Bedside." Neurotherapeutics 6, no. 4 (October 1, 2009): 713-37. https://doi.org/10.1016/j.nurt.2009.08.002. 
Raja, Aruna, Soha Ahmadi, Fernanda de Costa, Nan Li, and Kagan Kerman. "Attenuation of Oxidative Stress by Cannabinoids and Cannabis Extracts in Differentiated Neuronal Cells." Pharmaceuticals 13, no. 11 (November 2020): 328. https://doi.org/10.3390/ph13110328.

Ramirez, Cristina Lujan, Maria Alejandra Fanovich, and Maria Sandra Churio. "Chapter 4 Cannabinoids: Extraction Methods, Analysis, and Physicochemical Characterization." In Studies in Natural Products Chemistry, edited by Atta-ur-Rahman, 61:143-73. Elsevier, 2019. https://doi.org/10.1016/B978-0-444-64183-0.00004-X.

Rezvankhah, Amir, Zahra Emam-Djomeh, Mohammad Safari, Gholamreza Askari, and Maryam Salami. "Microwave-Assisted Extraction of Hempseed Oil: Studying and Comparing of Fatty Acid Composition, Antioxidant Activity, Physiochemical and Thermal Properties with Soxhlet Extraction.” Journal of Food Science and Technology 56, no. 9 (September 1, 2019): 41984210. https://doi.org/10.1007/s13197-019-03890-8.

Rice, Jessica, and Michelle Cameron. "Cannabinoids for Treatment of MS Symptoms: State of the Evidence." Current Neurology and Neuroscience Reports 18, no. 8 (June 19, 2018): 50. https://doi.org/10.1007/s11910-018-0859-X.

Romano, B, F Borrelli, I Fasolino, R Capasso, F Piscitelli, Mg Cascio, Rg Pertwee, et al. "The Cannabinoid TRPA1 Agonist Cannabichromene Inhibits Nitric Oxide Production in Macrophages and Ameliorates Murine Colitis.” British Journal of Pharmacology 169, no. 1 (2013): 213-29. https://doi.org/10.1111/bph.12120.

Rosenkrantz, Harris, George R. Thompson, and Monique C. Braude. "Oral and Parenteral Formulations of Marijuana Constituents." Journal of Pharmaceutical Sciences 61, no. 7 (July 1, 1972): 1106-12. https://doi.org/10.1002/jps.2600610715.

Routray, Winny, and Valérie Orsat. "Microwave-Assisted Extraction of Flavonoids: A Review." Food and Bioprocess Technology 5, no. 2 (February 1, 2012): 409-24. https://doi.org/10.1007/s11947-011-0573-Z.

Rovetto, Laura J., and Niccolo V. Aieta. "Supercritical Carbon Dioxide Extraction of Cannabinoids from Cannabis Sativa L." The Journal of Supercritical Fluids, IV Iberoamerican Conference on Supercritical Fluids - ProSCiba 2016, 129 (November 1, 2017): 16-27. https://doi.org/10.1016/j.supflu.2017.03.014.

"Supercritical Carbon Dioxide Extraction of Cannabinoids from Cannabis Sativa L." The Journal of Supercritical Fluids, IV Iberoamerican Conference on Supercritical Fluids - ProSCiba 2016, 129 (November 1, 2017): 16-27. https://doi.org/10.1016/j.supflu.2017.03.014.

Ruggieri, Michael R. "Cannabinoids: Potential Targets for Bladder Dysfunction." In Urinary Tract, edited by Karl-Erik Andersson and Martin C. Michel, 425-51. Handbook of Experimental 
Pharmacology. Berlin, Heidelberg: Springer, 2011. https://doi.org/10.1007/978-3-642-164996_20.

Russo, Ethan B. "Taming THC: Potential Cannabis Synergy and Phytocannabinoid-Terpenoid Entourage Effects." British Journal of Pharmacology 163, no. 7 (2011): 1344-64. https://doi.org/10.1111/j.1476-5381.2011.01238.x.

Russo, Ethan B. "The Case for the Entourage Effect and Conventional Breeding of Clinical Cannabis: No 'Strain,' No Gain.” Frontiers in Plant Science 9 (2019): 1969. https://doi.org/10.3389/fpls.2018.01969.

Russo, Ethan B., and Jahan Marcu. "Chapter Three - Cannabis Pharmacology: The Usual Suspects and a Few Promising Leads." In Advances in Pharmacology, edited by David Kendall and Stephen P. H. Alexander, 80:67-134. Cannabinoid Pharmacology. Academic Press, 2017. https://doi.org/10.1016/bs.apha.2017.03.004.

Rutz, Andreas. CPC distribution chromatography of cannabinoids. United States US10568863B2, filed February 29, 2016, and issued February 25, 2020. https://patents.google.com/patent/US10568863B2/en.

Sánchez-Rangel, Juan Carlos, Jorge Benavides, J. Basilio Heredia, Luis Cisneros-Zevallos, and Daniel A. Jacobo-Velázquez. "The Folin-Ciocalteu Assay Revisited: Improvement of Its Specificity for Total Phenolic Content Determination." Analytical Methods 5, no. 21 (October 10, 2013): 5990-99. https://doi.org/10.1039/C3AY41125G.

Serna-Loaiza, Sebastián, Johannes Adamcyk, Stefan Beisl, Christoph Kornpointner, Heidi Halbwirth, and Anton Friedl. "Pressurized Liquid Extraction of Cannabinoids from Hemp Processing Residues: Evaluation of the Influencing Variables.” Processes 8, no. 11 (November 2020): 1334. https://doi.org/10.3390/pr8111334.

Shin, Soo-Jeong, and Yong Joo Sung. "Improving Enzymatic Hydrolysis of Industrial Hemp (Cannabis Sativa L.) by Electron Beam Irradiation." Radiation Physics and Chemistry 77, no. 9 (September 1, 2008): 1034-38. https://doi.org/10.1016/j.radphyschem.2008.05.047.

Small, Ernest, and Arthur Cronquist. "A Practical and Natural Taxonomy for Cannabis." Taxon 25, no. 4 (1976): 405-35. https://doi.org/10.2307/1220524.

Smith, Richard, Hiroshi Inomata, and Cor Peters. Introduction to Supercritical Fluids: A Spreadsheet-Based Approach. Newnes, 2013.

Srinivas, K., J.w. King, J.k. Monrad, L.r. Howard, and C.m. Hansen. “Optimization of Subcritical Fluid Extraction of Bioactive Compounds Using Hansen Solubility Parameters.” Journal of Food Science 74, no. 6 (2009): E342-54. https://doi.org/10.1111/j.1750-3841.2009.01251.x. 
Stalikas, Constantine D. "Extraction, Separation, and Detection Methods for Phenolic Acids and Flavonoids." Journal of Separation Science 30, no. 18 (2007): 3268-95. https://doi.org/10.1002/jssc.200700261.

Subratti, Afraz, Lorale J. Lalgee, and Nigel K. Jalsa. "Liquified Dimethyl Ether (DME): A Green Solvent for the Extraction of Hemp (Cannabis Sativa L.) Seed Oil." Sustainable Chemistry and Pharmacy 12 (June 1, 2019): 100144. https://doi.org/10.1016/j.scp.2019.100144.

Teh, Sue-Siang, Brian E. Niven, Alaa El-Din A. Bekhit, Alan Carne, and Edward John Birch. "The Use of Microwave and Pulsed Electric Field as a Pretreatment Step in Ultrasonic Extraction of Polyphenols from Defatted Hemp Seed Cake (Cannabis Sativa) Using Response Surface Methodology." Food and Bioprocess Technology 7, no. 11 (November 1, 2014): 3064-76. https://doi.org/10.1007/s11947-014-1313-y.

Teräsvalli, Heini. "Extraction and Purification of Cannabidiol," 2020. https://lutpub.lut.fi/handle/10024/161311.

Thomas, David A., Tommi Virtanen, and Marilyn G. Wiebe. "Soxhlet Extraction of Mucic Acid from Fungal Biomass.” Separation Science and Technology 53, no. 6 (April 13, 2018): 903-9. https://doi.org/10.1080/01496395.2017.1407789.

Tomita, Karin, Siti Machmudah, Armando T. Quitain, Mitsuru Sasaki, Ryuichi Fukuzato, and Motonobu Goto. "Extraction and Solubility Evaluation of Functional Seed Oil in Supercritical Carbon Dioxide." The Journal of Supercritical Fluids, Special Issue - 10th International Symposium on Supercritical Fluids, 79 (July 1, 2013): 109-13. https://doi.org/10.1016/j.supflu.2013.02.011.

Touw, Mia. "The Religious and Medicinal Uses of Cannabis in China, India and Tibet." Journal of Psychoactive Drugs 13, no. 1 (January 1, 1981): 23-34. https://doi.org/10.1080/02791072.1981.10471447.

Tyśkiewicz, Katarzyna, Marcin Konkol, and Edward Rój. “The Application of Supercritical Fluid Extraction in Phenolic Compounds Isolation from Natural Plant Materials." Molecules 23, no. 10 (October 2018): 2625. https://doi.org/10.3390/molecules23102625.

Upadhyay, Swapna, and Madhulika Dixit. "Role of Polyphenols and Other Phytochemicals on Molecular Signaling." Oxidative Medicine and Cellular Longevity 2015 (June 9, 2015): e504253. https://doi.org/10.1155/2015/504253.

"Bread Supplementation with Hemp Seed Cake: A By-Product of Hemp Oil Processing." Accessed October 20, 2021. https://doi.org/10.1111/jfq.12159.

"Extraction of Naturally Occurring Cannabinoids: An Update." Accessed October 20, 2021. https://doi.org/10.1002/pca.2987. 
"Green Engineering: Green Composite Material, Biodiesel from Waste Coffee Grounds, and Polyurethane Bio-Foam - ProQuest." Accessed October 20, 2021. https://www.proquest.com/openview/ffa1d6535aa73300a0cf98687d2891c8/1?pqorigsite $=$ gscholar $\& \mathrm{cbl}=18750$.

Loosdrecht, A. A. van de, R. H. J. Beelen, G. J. Ossenkoppele, M. G. Broekhoven, and M. M. A. C. Langenhuijsen. "A Tetrazolium-Based Colorimetric MTT Assay to Quantitate Human Monocyte Mediated Cytotoxicity against Leukemic Cells from Cell Lines and Patients with Acute Myeloid Leukemia.” Journal of Immunological Methods 174, no. 1 (September 14, 1994): 311-20. https://doi.org/10.1016/0022-1759(94)90034-5.

"Survey of Minor Fatty Acids in Cannabis Sativa L. Fruits." Accessed October 20, 2021. https://www.druglibrary.org/olsen/hemp/IHA/jiha4107.html.

Valizadeh Derakhshan, Mehrab, Bahram Nasernejad, Farzin Abbaspour-Aghdam, and Mohammad Hamidi. "Oil Extraction from Algae: A Comparative Approach." Biotechnology and Applied Biochemistry 62, no. 3 (2015): 375-82. https://doi.org/10.1002/bab.1270.

Valizadeh Derakhshan, Mehrab, Bahram Nasernejad, Mitra Dadvar, and Mohammad Hamidi. "Pretreatment and Kinetics of Oil Extraction from Algae for Biodiesel Production." AsiaPacific Journal of Chemical Engineering 9, no. 5 (2014): 629-37. https://doi.org/10.1002/apj.1790.

Velasco, G., C. Sánchez, and M. Guzmán. “Anticancer Mechanisms of Cannabinoids.” Current Oncology 23, no. s1 (February 2016): 23-32. https://doi.org/10.3747/co.23.3080.

Velasco, Guillermo, Arkaitz Carracedo, Cristina Blázquez, Mar Lorente, Tania Aguado, Amador Haro, Cristina Sánchez, Ismael Galve-Roperh, and Manuel Guzmán. "Cannabinoids and Gliomas." Molecular Neurobiology 36, no. 1 (August 1, 2007): 60-67. https://doi.org/10.1007/s12035-007-0002-5.

Velasco, Guillermo, Cristina Sánchez, and Manuel Guzmán. “Towards the Use of Cannabinoids as Antitumour Agents." Nature Reviews Cancer 12, no. 6 (June 2012): 436-44. https://doi.org/10.1038/nrc3247.

Wang, Lijun, and Curtis L. Weller. "Recent Advances in Extraction of Nutraceuticals from Plants." Trends in Food Science \& Technology 17, no. 6 (June 1, 2006): 300-312. https://doi.org/10.1016/j.tifs.2005.12.004.

Wang, Mei, Yan-Hong Wang, Bharathi Avula, Mohamed M. Radwan, Amira S. Wanas, John van Antwerp, Jon F. Parcher, Mahmoud A. ElSohly, and Ikhlas A. Khan. "Decarboxylation Study of Acidic Cannabinoids: A Novel Approach Using Ultra-High-Performance Supercritical Fluid 
Chromatography/Photodiode Array-Mass Spectrometry." Cannabis and Cannabinoid Research 1, no. 1 (December 1, 2016): 262-71. https://doi.org/10.1089/can.2016.0020.

Whittle, Brian, Colin A. Hill, Ian R. Flockhart, David Victor Downs, Peter Gibson, and Gary William Wheatley. Extraction of pharmaceutically active components from plant materials. United States US7344736B2, filed August 14, 2002, and issued March 18, 2008. https://patents.google.com/patent/US7344736B2/en.

Wianowska, D., A. L. Dawidowicz, and M. Kowalczyk. "TRANSFORMATIONS OF TETRAHYDROCANNABINOL， TETRAHYDROCANNABINOLIC ACID AND CANNABINOL DURING THEIR EXTRACTION FROM CANNABIS SATIVA L." Zhurnal Analiticheskoi Khimii 70, no. 8 (2015). https://doi.org/10.7868/S0044450215080216.

Wijnen, Ben, Nigel Armstrong, Bram Ramaekers, Willem Witlox, Marie Westwood, Debra Fayter, Steve Ryder, et al. "Cannabidiol for Adjuvant Treatment of Seizures Associated with LennoxGastaut Syndrome and Dravet Syndrome: An Evidence Review Group Perspective of a NICE Single Technology Appraisal." PharmacoEconomics 38, no. 10 (October 1, 2020): 1043-53. https://doi.org/10.1007/s40273-020-00932-4.

Xie, Dao-Tao, Ya-Qin Wang, Yun Kang, Qiu-Fen Hu, Na-Ya Su, Jian-Ming Huang, Chun-Tao Che, and Ji-Xian Guo. "Microwave-Assisted Extraction of Bioactive Alkaloids from Stephania Sinica." Separation and Purification Technology 130 (June 10, 2014): 173-81. https://doi.org/10.1016/j.seppur.2014.04.026.

Yamauchi, Tatsuo, Yukihiro Shoyama, Yoko Matsuo, and Itsuo Nishioka. "Cannabigerol Monomethyl Ether, a New Component of Hemp." Chemical \& Pharmaceutical Bulletin 16, no. 6 (1968): 1164-65. https://doi.org/10.1248/cpb.16.1164.

Yang, Haotian, Rehan M. Villani, Haolu Wang, Matthew J. Simpson, Michael S. Roberts, Min Tang, and Xiaowen Liang. "The Role of Cellular Reactive Oxygen Species in Cancer Chemotherapy." Journal of Experimental \& Clinical Cancer Research 37, no. 1 (November 1, 2018): 266. https://doi.org/10.1186/s13046-018-0909-x.

Zhang, Qing-Wen, Li-Gen Lin, and Wen-Cai Ye. "Techniques for Extraction and Isolation of Natural Products: A Comprehensive Review." Chinese Medicine 13, no. 1 (April 17, 2018): 20. https://doi.org/10.1186/s13020-018-0177-x. 
